\title{
The Role of PEG 6000 and PVP as Stabilizing and Surfactant Agents in the Photoelectrochemical Properties of $\mathrm{BiVO}_{4}$ Monoclinic Structure
}

\author{
Marcelo R. S. Pelissari, ${ }^{a}$ Luis Vicente A. Scalvi ${ }^{b}$ and Luiz Henrique Dall'Antonia ${ }^{\circledR}, c$ \\ ${ }^{a}$ Colégio Técnico Industrial, Faculdade de Engenharia, Universidade Estadual Paulista, \\ 17033-260 Bauru-SP, Brazil \\ ${ }^{b}$ Departamento de Física, Faculdade de Ciências, Universidade Estadual Paulista, \\ 17033-360 Bauru-SP, Brazil

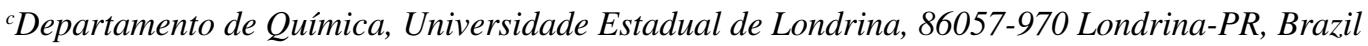

\begin{abstract}
Nanocrystalline $\mathrm{BiVO}_{4}$ on monoclinic phase was obtained by a modified-solution combustion synthesis (SCS) using poly(ethylene glycol) (PEG 6000) and polyvinylpyrrolidone (PVP) as stabilizing and surfactant agents, respectively. An active photoanode was built using a simple procedure by dip-coating deposition process on fluorine-doped tin dioxide (FTO). The structure, morphology and optical properties of $\mathrm{FTO} / \mathrm{BiVO}_{4}$ photoanode were evaluated by means of $\mathrm{X}$-ray diffraction (XRD), Raman spectroscopy, scanning electron microscopy (SEM) and diffuse reflectance UV-Vis spectroscopy. The photoelectrochemical performance measurements were carried out by linear sweep voltammetry (LSV), chronoamperometry and electrochemical impedance spectroscopy (EIS) under InGaN blue light emitting diode (LED) illumination condition (about $450 \mathrm{~nm}$ ). In $\mathrm{Na}_{2} \mathrm{SO}_{4}$ electrolyte solution, the electrode has presented better photoelectroactivity than in $\mathrm{NaNO}_{3}$ solution, as evidenced by photoelectrochemical parameters such as: the highest photocurrent density $\left(\mathrm{j}_{\mathrm{s}}\right)$ value, cathodic shifts of the onset potential (OP) and lower charge-transfer resistence $\left(\mathrm{R}_{\mathrm{ct}}\right)$. In the methyl orange (MO) degradation reaction the $\mathrm{FTO} / \mathrm{BiVO}_{4}$ electrode has presented high photoelectroactivity, where the estimated kinetic constant rate $\left(\mathrm{k}_{\text {obs }}\right)$ is $4.74 \times 10^{-3}$ and $7.54 \times 10^{-3} \mathrm{~min}^{-1}$ in $\mathrm{NaNO}_{3}$ and $\mathrm{Na}_{2} \mathrm{SO}_{4}$ solutions, respectively. This remarkable performance of the as-prepared electrode is due to the morphological $\mathrm{BiVO}_{4}$ structure, with elongated-shape nano-sized domain particles, besides the considerable porosity and roughness levels on electrode surface.
\end{abstract}

Keywords: monoclinic $\mathrm{BiVO}_{4}$, SCS, dip-coating process, PEG 6000, PVP, photoelectrochemical performance

\section{Introduction}

Monoclinic bismuth vanadate $\left(\mathrm{BiVO}_{4}\right)$ structure in the thin films configuration presents high technological potential, and may be used as electrode material, playing as photoanode in a wide range of systems. ${ }^{1}$ In this context, some application stands out, such as: photocatalysis, ${ }^{2,3}$ water splitting involving the oxygen evolution reaction $(\mathrm{OER})^{4-7}$ and photoelectrooxidation of a wide range of organic compounds in aqueous media, such as dyes, ${ }^{8,9}$ pesticides, ${ }^{10}$ antibiotics,${ }^{11,12}$ and others.

In the last two decades, $\mathrm{BiVO}_{4}$ has been highlighted as one of the most studied semiconductor material worldwide

*e-mail: luizh@uel.br by different research groups due to its unique properties. ${ }^{13}$ It has capability to absorb visible light for generation of charge carriers (electron-hole pairs), due to its narrow band gap energy in the order of $2.4 \mathrm{eV}$ (energy within the visible range of the electromagnetic spectrum). ${ }^{1,13}$ This narrow band gap energy provides this semiconductor material the capability of using the solar light for excitation, which somewhat minimizes the cost of implementing certain devices where $\mathrm{BiVO}_{4}$ acts as a photoanode. ${ }^{13,14}$ Another interesting feature of this semiconductor material is its high chemical stability in aqueous media, where it can be used repetitively numerous times in certain situations (several cycles of use) where corrosion is not observed or negligibly. ${ }^{3,15}$ This feature implies in reproducibility of data and long use, which is a very important parameter 
for technological application. In addition, $\mathrm{BiVO}_{4}$ is a non-toxic material for human health, being an important factor towards its use. ${ }^{3,13-15}$

The use of $\mathrm{BiVO}_{4}$ thin films requires the designed device to have a conductive substrate due to the high electrical resistance of the semiconductor film itself. ${ }^{16}$ Conductive fluorine-doped tin dioxide (FTO) and indium tin oxide (ITO) substrates are widely used due to their low electrical resistance. The performance of photoanode, in this case the $\mathrm{BiVO}_{4}$ film deposited on FTO or ITO conductive substrates, depends on several factors, such as: a good conductive substrate, the technique used to deposit the material in the form of film, the film deposition process and the electrolyte solution used. ${ }^{13}$ One of the techniques for obtaining this $\mathrm{BiVO}_{4}$ material is the solution combustion synthesis (SCS) process, where the monoclinic phase of $\mathrm{BiVO}_{4}$ is easily obtained with low cost during practicality the whole process. ${ }^{17,18}$ In this SCS process a bluish or greenish solution is obtained and by a dip-coating or spin coating process the film is deposited with controlled thickness, according to the required amount of layers and thickness..$^{9,19}$ The SCS process has the advantage of being a fast, self-sustaining exothermic chemical reaction between metal salts and urea, which in this case acts as a process fuel, in addition to the use of a stabilizing agent, usually citric acid. ${ }^{16-18}$ Some modifications of the SCS process have been published. ${ }^{20,21}$ For example, in the paper of Serafim et al.,${ }^{20}$ the authors synthesized $\mathrm{BiVO}_{4}$ nanoparticles by the SCS process using different fuels, urea, alanine and glycine. The results showed that when alanine was used as a fuel, a material with higher electroactivity in methylene blue photodegradation reaction was obtained.

The choice of electrolyte solution is also fundamental factor to the electroactivity of the $\mathrm{BiVO}_{4}$ photoanode, because the electrolyte solution is directly related to the charge transfer kinetics at the photoanode/electrolyte interface. ${ }^{22,23}$

In this context, the present paper proposes a photoelectrochemical performance evaluation of monoclinic $\mathrm{BiVO}_{4}$ phase in the thin film configuration, obtained by the SCS/dip-coating process. The paper aims showing the role of poly(ethylene glycol) (PEG 6000) and polyvinylpyrrolidone (PVP) as stabilizing and surfactant agents, respectively, in the structural and morphological properties of obtained $\mathrm{BiVO}_{4}$ material. The incorporation of these agents generated an enhancement in its photoelectrochemical activity. Along with the careful photoelectrochemical investigation, the performance of these electrodes face to the methyl orange (MO) electrochemical and photoelectrochemical degradation reaction was also analyzed.

\section{Experimental}

\section{Materials and reagents}

All used chemicals reagents are of analytical grade, produced by Sigma-Aldrich (São Paulo, SP, Brazil) and used without any further purification. The reagents are: poly(ethylene glycol) (PEG 6000; molecular weight $(\mathrm{PM})=5,400-6,600$; impurities $=5 \mathrm{ppm}$ of heavy metals), polyvinylpyrrolidone (PVP; $\mathrm{PM}=40,000$; purity level $=98 \%$ ), bismuth nitrate hexahydrate $\left(\mathrm{Bi}\left(\mathrm{NO}_{3}\right)_{3} \cdot 6 \mathrm{H}_{2} \mathrm{O}\right.$; purity level $\left.=98 \%\right)$, nitric acid $\left(\mathrm{HNO}_{3}\right.$; purity level $=65-67 \%)$, ammonium hydroxide $\left(\mathrm{NH}_{4} \mathrm{OH}\right.$; $28-30 \%$ of $\mathrm{NH}_{3}$ ), citric acid (purity level > 99\%), urea (purity level $=99 \%)$, methyl orange $(\mathrm{MO}$; purity level $=85 \%)$, acetone (purity level $=99.5 \%)$, sodium nitrate $\left(\mathrm{NaNO}_{3}\right.$; purity level $=99 \%)$ and sodium sulfate $\left(\mathrm{Na}_{2} \mathrm{SO}_{4}\right.$; purity level $=99 \%)$. The solutions were prepared using ultrapure water (Sigma-Aldrich, São Paulo, SP, Brazil). Fluorinedoped tin oxide (FTO, resistivity $(\rho)=7 \Omega \mathrm{cm}^{-2}$ ) was used as conductor substrate. Dip-coating equipment was used for film deposition, as well the muffle furnace for the thermal annealing.

Synthesis of green-blue solution of $\mathrm{BiVO}_{4}$ precursor and the construction of $\mathrm{FTO} / \mathrm{BiVO}_{4}$ photoanode

The green-blue solution of $\mathrm{BiVO}_{4}$ precursor was obtained by the solution combustion synthesis (SCS) process as described in previous published papers. ${ }^{9,16-18}$ Details on $\mathrm{BiVO}_{4}$ synthesis, that include the steps of SCS procedure and also the amount of used reagents, can be seen in the Supplementary Information (SI) section in a schematic diagram (Figure S1). Particularly in the case of this paper, in addition to the citric acid used as a stabilizing agent, poly(ethylene glycol) (PEG 6000) was also used, unlike the mentioned papers that used only citric acid. Besides, polyvinylpyrrolidone (PVP) is also used in this synthesis process as surfactant. In the SCS process, urea act as fuel of self-sustaining chemical reaction. It will be shown in this paper that the combination of these two stabilizing agents, citric acid and PEG 6000, and by the action of the PVP as surfactant, provide better photoelectrochemical

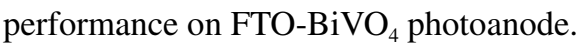

Four samples were obtained, which will be from now on called $\mathrm{BiVO}_{4}(1), \mathrm{BiVO}_{4}(2), \mathrm{BiVO}_{4}(3)$ and $\mathrm{BiVO}_{4}$ (4). The $\mathrm{BiVO}_{4}(1)$ was obtained exactly how described in previous published papers, ${ }^{9,16-18}$ using citric acid as stabilizing agent, which is the typical conventional SCS process (Figure S1). For the $\mathrm{BiVO}_{4}(2), \mathrm{BiVO}_{4}(3)$ and $\mathrm{BiVO}_{4}(4)$, besides the citric acid, we have added PVP, PEG 6000 and PVP + PEG 6000, 
respectively. For the $\mathrm{BiVO}_{4}(2), 0.4 \mathrm{~g}$ of PVP was added in the first step of SCS synthesis along the bismuth precursor resulting in the solution called "solution A". In the second step of synthesis $0.2 \mathrm{~g}$ of PVP was added along the vanadium precursor resulting in the solution called "solution B". Finally, solutions A and B are mixed and left in muffle furnace at $90{ }^{\circ} \mathrm{C}$ for $20 \mathrm{~h}$. After this time, a material with gelatinous consistency and green-blue color is obtained. We have chosen to keep the mass ratio $(\mathrm{m} / \mathrm{m})$ of PVP equal to the citric acid mass of the SCS process in each step. To obtain the $\mathrm{BiVO}_{4}(3)$ the same procedure that was used to obtain $\mathrm{BiVO}_{4}(2)$ is used, where the unique difference is that in the place of PVP, the PEG 6000 reagent in the same mass ratio of citric acid is added. Finally, to obtain the $\mathrm{BiVO}_{4}(4)$ the same procedure that was used to obtain $\mathrm{BiVO}_{4}(2)$ and $\mathrm{BiVO}_{4}(3)$ is used. Here, PVP and PEG 6000 are added simultaneously to citric acid in the mass ratio $(\mathrm{m} / \mathrm{m})$ used above to the samples $\mathrm{BiVO}_{4}(2)$ and $\mathrm{BiVO}_{4}(3)$.

Before deposition of $\mathrm{BiVO}_{4}$ onto fluorine-doped tin oxide (FTO, $\rho=7 \Omega \mathrm{cm}^{-2}$ ), the substrate surface was cleaned in an ultrasonic bath using acetone for $30 \mathrm{~min}$. After the cleaning procedure, the substrate was dried in muffle furnace at $100{ }^{\circ} \mathrm{C}$ for $1 \mathrm{~h}$. Then, from the material with gelatinous consistency, an aqueous solution was obtained through dilution, and the FTO substrate was sequentially dipped inside this solution using the dip rate of $10 \mathrm{~cm} \mathrm{~min}{ }^{-1}$. Ten layers were deposited, and between each layer, the sample was dried for $10 \mathrm{~min}$ under room atmosphere conditions, followed by heating at $400{ }^{\circ} \mathrm{C}$ for another $10 \mathrm{~min}$. After deposition deposited layers, the film is thermally annealed at $500^{\circ} \mathrm{C}$ for $1 \mathrm{~h}$.

\section{Physical characterization}

All samples were characterized by X-ray diffraction (XRD), Raman spectroscopy, diffuse reflectance and scanning electron microscopy (SEM). XRD measurements were carried out using a PANanalytical diffractometer, model X'Pert PRO MPD (Malvern Panalytical Ltd), with the $\mathrm{Cu} \mathrm{K \alpha}$ (1.54056 $\AA$ ) radiation, coupled to a nickel filter, whit an applied tension of $40 \mathrm{kV}$ and the current of $15 \mathrm{~mA}$. The data are collected in $2 \theta$ mode with 0.04 of step in the angular range of $10-80^{\circ}$. Raman scattering data were obtained through a Bruker FT, model Raman RFS 100 spectrometer (Bruker Corporation, Billerica, Massachusetts, USA), with excitation at 1,064 nm, obtained through the Nd:YAG laser with $200 \mathrm{~mW}$ power. Diffuse reflectance spectra were determined with the help of Shimadzu UV-3101 PC equipment (Shimadzu Scientific Instruments Inc., Maryland, USA) within the range 190-900 nm. SEM images were obtained in a Quanta
200-FEI microscope (FEI Company, Hillsboro, Oregon, USA) with $30 \mathrm{kV}$ of applied voltage.

\section{Photoelectrochemical measurements}

An electrochemical cell with three electrodes were used for the photoelectrochemical experiments, where an $\mathrm{Ag}$ / $\mathrm{AgCl}\left(3 \mathrm{~mol} \mathrm{~L}^{-1} \mathrm{KCl}\right)$ electrode is the reference, a platinum wire is the counter electrode, and the $\mathrm{BiVO}_{4}$ film as the working electrode (the geometrical electrode area in contact with the solution is set to $1.08 \mathrm{~cm}^{2}$ ). A blue InGaN light emitting diode (LED) with average wavelength of $450 \mathrm{~nm}$ and average power of $15 \mathrm{~mW}$ was used as visible light source. The $\mathrm{BiVO}_{4}$ surface illumination was accomplished from the sample front-side, with the light source positioned $5 \mathrm{~cm}$ distant from the film. The photoelectrochemical characterization procedures are carried out by linear sweep voltammetry (LSV), chronoamperometry and electrochemical impedance spectroscopy (EIS) techniques, through a potentiostat/galvanostat PalmSens, version 4, controlled by PSTrace 5 software, using $5 \mathrm{~mL}$ of $0.1 \mathrm{~mol} \mathrm{~L}{ }^{-1}$ sodium nitrate $\left(\mathrm{NaNO}_{3}\right)$ and sodium sulfate $\left(\mathrm{Na}_{2} \mathrm{SO}_{4}\right)$ as electrolyte solutions. In addition, for the EIS measurements the Nyquist and Bode plots were acquired at $+1.4 \mathrm{~V}$ (vs. $\mathrm{Ag} / \mathrm{AgCl}$ ) with $\mathrm{AC}$ amplitude of $20 \mathrm{mV}$ and frequency range of $0.05-100,000 \mathrm{~Hz}$.

The performance test of methyl orange (MO) degradation reaction was carried out using $5 \mathrm{~mL}$ of $0.1 \mathrm{mmol} \mathrm{L}^{-1}$ of $\mathrm{MO}$ in $0.1 \mathrm{~mol} \mathrm{~L}^{-1} \mathrm{NaNO}_{3}$ and $\mathrm{Na}_{2} \mathrm{SO}_{4}$ electrolyte solutions. The electrolysis measurements were carried out by controlled potential of $+0.8 \mathrm{~V}$ in different reaction time, in the dark and under illumination conditions (InGaN LED). After each electrolysis test, aliquots of solutions were collected, and the $\mathrm{UV}$-Vis absorbance spectra were taken to verify the relative amount (percentage) of MO degraded. These spectra were obtained with the help of Shimadzu UV-3101 PC equipment.

\section{Results and Discussion}

\section{Characterization of samples}

The global chemical reaction of monoclinic $\mathrm{BiVO}_{4}$ structure formation, using the SCS process, can be represented through reaction $1 .^{20}$

$$
\begin{array}{r}
\mathrm{Bi}\left(\mathrm{NO}_{3}\right)_{3} \cdot 5 \mathrm{H}_{2} \mathrm{O}+\mathrm{NH}_{4} \mathrm{VO}_{3}+3 \mathrm{CH}_{4} \mathrm{~N}_{2} \mathrm{O}+{ }^{3} / \mathrm{O}_{2} \rightarrow \\
\mathrm{BiVO}_{4}+5 \mathrm{~N}_{2}+3 \mathrm{CO}_{2}+13 \mathrm{H}_{2} \mathrm{O}
\end{array}
$$

This reaction is characterized by a redox process, where the bismuth nitrate acts as oxidizing agent, while the urea fuel acts as reducing agent. ${ }^{17,18}$ 
The amount of gases released during this process leads to heat dissipation, considering that the process is exothermic, keeping the system thermal stability. ${ }^{17-20}$ The reagents citric acid and PEG 6000 does not show up in the reaction 1 , since they act as stabilizing agents of $\mathrm{Bi}^{3+}$ and $\mathrm{VO}_{3}{ }^{-}$, avoiding the evaporation of these precursors during the whole synthesis process. ${ }^{24} \mathrm{PVP}$ also does not appear in equation 1 and, in addition to stabilizing agent role, it also plays a fundamental role as surfactant agent, acting as viscosity regulator in the solution. ${ }^{25}$ Moreover, these stabilizing and surfactant agents help on the solution thermodynamic stability and may guide the particle morphology, and leads to nanometric dimensions structures. ${ }^{26}$

Considering the influence of PEG $6000\left[\mathrm{HO}\left(\mathrm{C}_{2} \mathrm{H}_{4} \mathrm{O}\right)_{\mathrm{n}} \mathrm{H}\right]$ in the SCS process, its stabilizing effect is related to its oxygen ions which accomplish strong coordination effect on $\mathrm{Bi}^{3+}$ and $\mathrm{VO}_{3}{ }^{-}$ions. Associated to this effect, the high amount of hydrogen bonds between the PEG 6000 and water creates the thermodynamic stability in the solution. ${ }^{24,26}$ For instance, Ribeiro et al. ${ }^{24}$ report a $\mathrm{BiVO}_{4}$ monoclinic Scheelite phase in the form of films, successfully obtained based on a quick one-step procedure employing different alcohol as solvents and stabilizing agents (ethanol, ethyleneglycol, PEG 300 and PEG 400). Different morphologies, crystal growth rate, crystallite sizes and thicknesses were obtained for the $\mathrm{BiVO}_{4}$ films, depending on the type of precursor solvent, with significant effects on the photocurrents.

On the other hand, PVP $\left[\left(\mathrm{C}_{6} \mathrm{H}_{9} \mathrm{NO}\right)_{n}\right]$, besides playing as stabilizing agent of $\mathrm{Bi}^{3+}$ and $\mathrm{VO}_{3}{ }^{-}$ions (due to polarity effect of carbonyl group of PVP structure), also performs as dispersing agent, which influences the solution viscosity, through hydrogen interaction between PVP and water molecules. ${ }^{25}$ Published reports ${ }^{25,27-31}$ have shown this double effect of PVP in the synthesis of a great variety of materials, such as $\mathrm{BiVO}_{4},{ }^{25} \mathrm{Y}_{2} \mathrm{O}_{3}: \mathrm{Eu}^{3+},{ }^{27} \mathrm{Gd}_{2} \mathrm{O}_{2} \mathrm{~S}: \mathrm{Ln}^{3+}(\mathrm{Ln}=\mathrm{Eu}, \mathrm{Tb}),{ }^{28}$ $\mathrm{CdS},{ }^{29} \mathrm{GdVO}_{4},{ }^{30} \mathrm{YVO}_{4},{ }^{31}$ among others. Wang et al. ${ }^{25}$ obtained $\mathrm{BiVO}_{4}$ nanofibers and porous nanostructures by electrospinning method using PVP to adjust the viscosity and spinnability of the electrospinning sol. The results showed that the slow decomposition and combustion of PVP prevented rapid crystal growth of $\mathrm{BiVO}_{4}$, leading to structures with nano-size domain, besides preventing surface defects. In another work, Cui et al. ${ }^{27}$ report a facile hydrothermal method to obtainment of monodispersed $\mathrm{Y}_{2} \mathrm{O}_{3}: \mathrm{Eu}^{3+}$ colloidal spheres with controllable size (140-430 nm). According to the authors, the uniform and narrowly size-distributed $\mathrm{Y}_{2} \mathrm{O}_{3}: \mathrm{Eu}^{3+}$ spheres are due to the PVP addition, that act as both surfactant and stabilizing agents.

In the present work, the electrode obtained in the synthesis process where PEG 6000 is used in conjunction with PVP has presented the best electrochemical performance, as will be shown below. In this case, the added effect of PEG 6000-PVP has led to better species dispersion in the reaction media, along with stabilization of $\mathrm{Bi}^{3+}$ and $\mathrm{VO}_{3}{ }^{-}$ions, allowing morphological and structural control of the nanometric dimensions during the slow process of crystal growth, as can be seen by the SEM images shown below.

A proposed mechanism considering the jointly action of nitric acid, PEG 6000 and PVP in the formation of $\mathrm{BiVO}_{4}$ crystals may be seen in SI section, Figure S2. Steps 1 and 2 correspond to the stabilization of $\mathrm{Bi}^{3+}$ and $\mathrm{VO}_{3}^{-}$ions by nitric acid and PEG 6000, connected to dispersion of stabilized ions by PVP (this mechanism illustrates the obtainment of sample $\left.\mathrm{BiVO}_{4}(4)\right)$. A higher stabilization occurs due to the strong coordination of oxygen atoms in the PEG structure. Following these steps, a slower step (20 h, which is the synthesis time) takes place, where nucleation and $\mathrm{BiVO}_{4}$ crystal growth in a PVP matrix occurs, keeping the particle dispersion. Finally, after the films deposition process and thermal annealing, the $\mathrm{BiVO}_{4}$ monoclinic structure is obtained.

The diffraction patters of all samples $\left(\mathrm{BiVO}_{4}(1)\right.$, $\mathrm{BiVO}_{4}(2), \mathrm{BiVO}_{4}(3)$ and $\left.\mathrm{BiVO}_{4}(4)\right)$ can be seen in Figure 1a. In all the samples the same diffraction peaks appears, at the same 2-theta position. The diffracted peaks marked by the symbol $(\diamond)$ belong to the $\mathrm{BiVO}_{4}$ monoclinic structure as inferred from the PDF 75-1867 file of the PCPDFWIN software (version 2.4, JCPDS-ICDD). No peaks related to crystalline impurities or others $\mathrm{BiVO}_{4}$ phases have been detected, indicating that the monoclinic $\mathrm{BiVO}_{4}$ structure is highly dominant. This high purity level of the obtained material demonstrates that the synthesis process adopted here, SCS/dip-coating process, is highly efficient for obtainment of monoclinic $\mathrm{BiVO}_{4}$. Other diffracted peaks marked by the symbol $(\Delta)$ in Figure 1a belong to the FTO substrate $\left(\mathrm{SnO}_{2}: \mathrm{F}\right.$ crystalline phase). A good evaluation of the average crystallite size of $\mathrm{BiVO}_{4}$ material is done through the Scherrer formula ${ }^{32}$ using the (112) diffraction plane $\left(2 \theta=29^{\circ}\right)$, which is the most intense. The values of average crystallite size can be seen in SI section (Table $\mathrm{S} 1$ ). These results show a slight variation in the average crystallite size between each sample.

Raman spectra for $\mathrm{BiVO}_{4}$ films are shown in Figure $1 \mathrm{~b}$. The Raman shift of the most intense vibrational band is a little different for the samples $\mathrm{BiVO}_{4}(1), \mathrm{BiVO}_{4}(2)$, $\mathrm{BiVO}_{4}(3)$ and $\mathrm{BiVO}_{4}(4)$, being the values 834, 833, 829 and $827 \mathrm{~cm}^{-1}$, respectively, that corresponds to the shorter symmetric $\mathrm{V}-\mathrm{O}$ stretching mode $(\mathrm{A} g) .{ }^{33}$ These values are in good agreement with literature, where for the $\mathrm{BiVO}_{4}$ monoclinic phase the symmetric $\mathrm{V}-\mathrm{O}$ stretching mode 

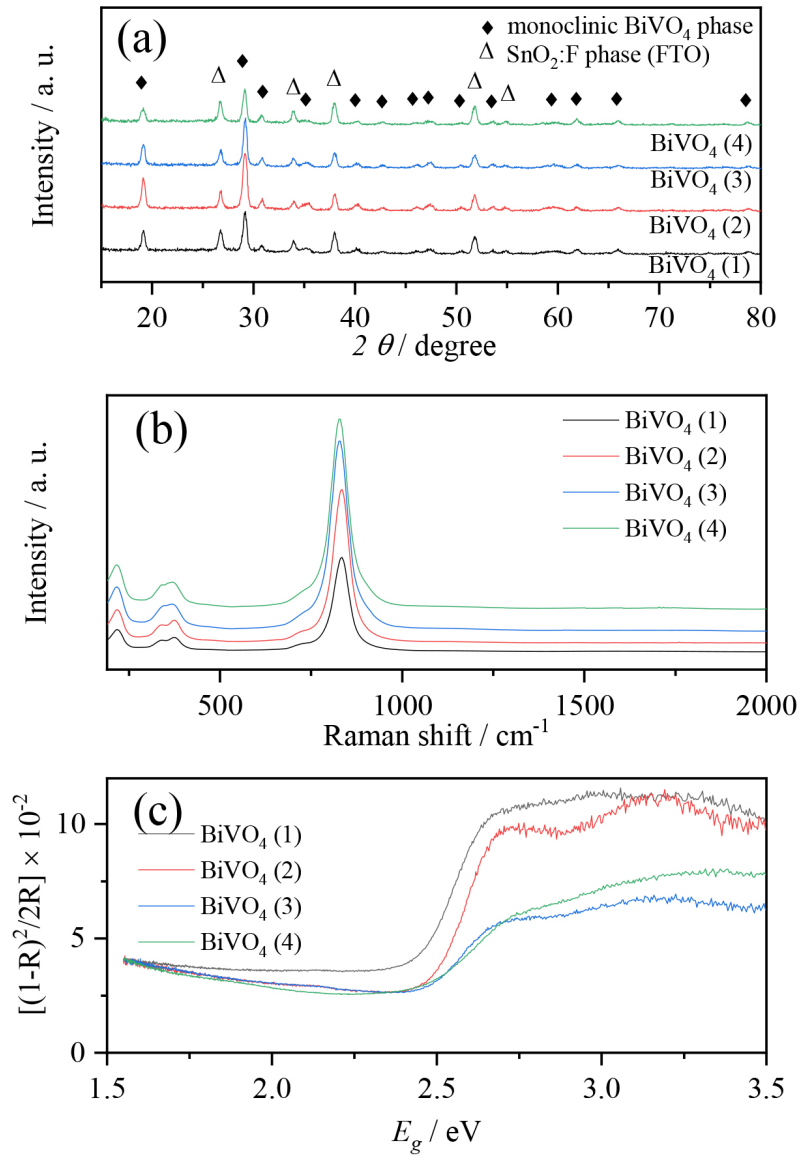

Figure 1. (a) XRD patterns, (b) Raman shift and (c) band gap evaluation (Kubelka-Munk model from UV-Vis diffuse reflectance) for $\mathrm{BiVO}_{4}(1)$, $\mathrm{BiVO}_{4}(2), \mathrm{BiVO}_{4}(3)$ and $\mathrm{BiVO}_{4}(4)$ samples.

can appear in the range $826-832 \mathrm{~cm}^{-1} \cdot 33,34$ The more intense Raman shift for $\mathrm{BiVO}_{4}$ is located about $830 \mathrm{~cm}^{-1}$, and this band location which can be used to obtain information on $\mathrm{BiVO}_{4}$ crystalline structure. Then, using this intense vibrational band it is possible to obtain an estimative of the vanadium-oxygen bond length by equation 2 , and as discussed in previously published works..$^{24,35}$

$v_{\mathrm{V}-\mathrm{O}}\left(\mathrm{cm}^{-1}\right)=21349 \times \exp \left[-1.9176 \times \mathrm{R}_{\mathrm{V}-\mathrm{O}}(\AA)\right]$

where $v_{\mathrm{V}-\mathrm{O}}$ is the symmetric $\mathrm{V}-\mathrm{O}$ stretching mode $(\mathrm{A} g)$ and $\mathrm{R}_{\mathrm{V}-\mathrm{O}}$ is the vanadium-oxygen bond length. Using this equation, the estimated values for the average $\mathrm{V}-\mathrm{O}$ bond lengths obtained are 1.690,1.691, 1.694 and $1.696 \AA$ for the samples $\mathrm{BiVO}_{4}(1), \mathrm{BiVO}_{4}(2), \mathrm{BiVO}_{4}(3)$ and $\mathrm{BiVO}_{4}(4)$, respectively, (Table 1). These values are in good agreement with the reported values in a paper by Tokunaga et $a l .{ }^{36}(1.69 \AA)$ and by Ribeiro et al. ${ }^{24}(1.688 \AA$ for $\mathrm{BiVO}_{4} / \mathrm{FTO}$-ethanol; $1.684 \AA$ for $\mathrm{BiVO}_{4} / \mathrm{FTO}$-ethyleneglycol; $1.688 \AA$ for $\mathrm{BiVO}_{4} / \mathrm{FTO}-\mathrm{PEG} 300$ and $1.689 \AA$ for $\mathrm{BiVO}_{4} / \mathrm{FTO}-\mathrm{PEG} 400$ ), that gives the vanadium-oxygen bond length in the monoclinic crystal structure of $\mathrm{BiVO}_{4}$ material. Other peaks are also observed, for instance, the weaker band at $717 \mathrm{~cm}^{-1}$ corresponds to long $(\mathrm{Ag})$ asymmetric $\mathrm{V}-\mathrm{O}$ stretching mode. ${ }^{24}$ Two peaks in the lowest wavenumber region at 337 and $375 \mathrm{~cm}^{-1}$ are related to the asymmetric $(\mathrm{A} g)$ and symmetric $(\mathrm{B} g)$ deformations of $\mathrm{VO}_{4}{ }^{3-}$ tetrahedron, respectively. ${ }^{33,34}$ It is also possible to identify a peak of about $215 \mathrm{~cm}^{-1}$, which is associated to the external mode rotation/translation of $\mathrm{BiVO}_{4}$ crystal. ${ }^{24} \mathrm{In}$ the range 1000 to $2000 \mathrm{~cm}^{-1}$ no peak is observed, which is a good indication of the non-existence of carbon chemical species residues, that could be adsorbed on the samples, coming from the SCS process, related to combustion of organic compounds during the synthesis process.

Table 1. Band gap energy values and average $\mathrm{V}-\mathrm{O}$ bond length of $\mathrm{BiVO}_{4}$ films

\begin{tabular}{lcl}
\hline Sample & Band gap energy / eV & $\mathrm{R} / \AA$ \\
\hline $\mathrm{BiVO}_{4}(1)$ & 2.36 & 1.690 \\
$\mathrm{BiVO}_{4}(2)$ & 2.43 & 1.691 \\
$\mathrm{BiVO}_{4}(3)$ & 2.33 & 1.694 \\
$\mathrm{BiVO}_{4}(4)$ & 2.27 & 1.696 \\
\hline
\end{tabular}

$\mathrm{R}$ : vanadium-oxygen bond length.

Figure 1c shows the band gap energy evaluation using the Kubelka-Munk model, ${ }^{30}$ from the diffuse reflectance UV-Vis spectra of all obtained samples. The band gap energy $\left(E_{g}\right)$ values were calculated using the equations 3 and $4 .{ }^{30}$

$\alpha=F(R)=\frac{(1-R)^{2}}{2 R}$

$(\alpha h v)^{2}=A\left(h v-E_{g}\right)$

In these two equations, $F(R)$ is the Kubelka-Munk function, $\mathrm{R}$ is the absolute reflectance, $\alpha$ is the absorption coefficient, $\mathrm{h}$ is the Planck constant, $v$ is the frequency of light, $\mathrm{A}$ is a constant and $\mathrm{E}_{\mathrm{g}}$ is the band gap energy. The obtained values of band gap energy are 2.36, 2.43, 2.33 and $2.27 \mathrm{eV}$ for sample $\mathrm{BiVO}_{4}(1), \mathrm{BiVO}_{4}(2), \mathrm{BiVO}_{4}(3)$ and $\mathrm{BiVO}_{4}(4)$, respectively. These values are summarized in Table 1. Although a slight variation is observed between each sample, these band gap values are between 2.3 and $2.4 \mathrm{eV}$, in good agreement with previous published papers. ${ }^{16,17,37,38}$

SEM topographic images of all the samples $\left(\mathrm{BiVO}_{4}\right.$ film deposited on FTO substrate) can be seen in Figure 2. The topographic image with magnification of $5000 \times$ shows the non-homogeneous surface to the $\mathrm{BiVO}_{4}(1), \mathrm{BiVO}_{4}(2)$, $\mathrm{BiVO}_{4}(3)$ and $\mathrm{BiVO}_{4}(4)$ samples. Concerning images of $\mathrm{BiVO}_{4}(1), \mathrm{BiVO}_{4}(2)$ and $\mathrm{BiVO}_{4}(3)$ samples, it is possible 
to observe some regions formed by particles with different sizes and with some micro aggregates, which in general, are quite similar. For the sample $\mathrm{BiVO}_{4}$ (2) which was obtained using PVP as surfactant agent, a better dispersion of particles is observed, which can prove the action of PVP in the SCS process. In the sample $\mathrm{BiVO}_{4}$ (3), the action of PEG 6000 as stabilizing agent is also evident, considering that the particles are smaller than particles of sample $\mathrm{BiVO}_{4}$ (1) (obtained without PEG 6000). On the other hand, the combination of PEG 6000 and PVP has shown quite efficient as viewed in the SEM images for sample $\mathrm{BiVO}_{4}(4)$.
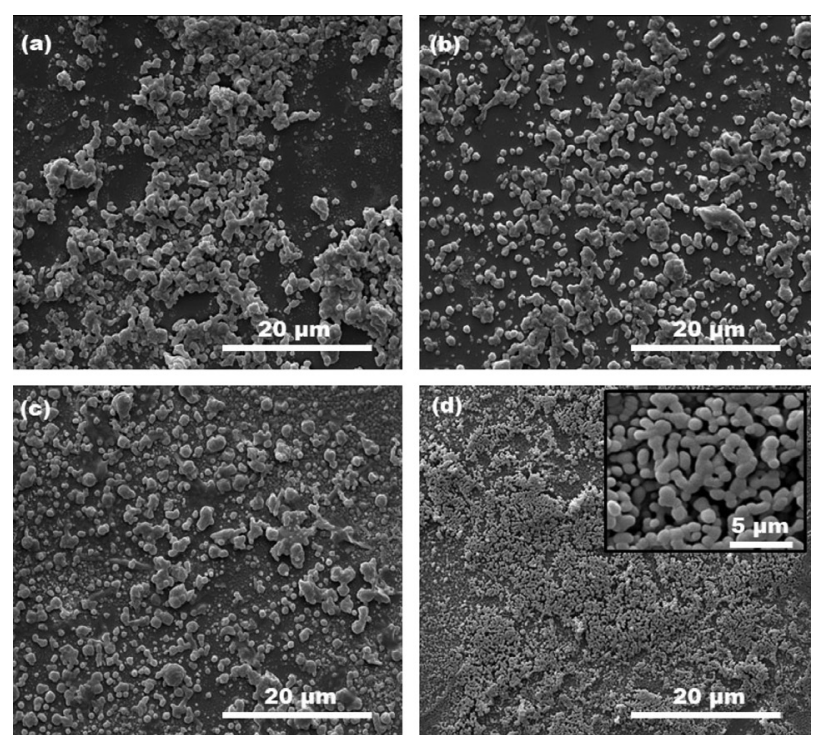

Figure 2. SEM surface images of (a) $\mathrm{BiVO}_{4}$ (1), (b) $\mathrm{BiVO}_{4}$ (2), (c) $\mathrm{BiVO}_{4}$ (3) and (d) $\mathrm{BiVO}_{4}$ (4) samples whit magnification of 5000x. Inset in (d): magnification of 20000x.

Inserted image in Figure 2d shows the high level of dispersion and homogeneity in the particles distribution in all the analyzed area. The size of these particles is much smaller than particles of other three samples, besides the different shape, which in this case consists of particles with elongated shape, like rods, as observed by the inserted image in the top right corner of the respective image, with magnification of $20000 \times$. In addition, the combination of PEG 6000 and PVP, as stabilizing and surfactant agents in the SCS process, provides also increase in the porosity and roughness levels in the sample, being quite interesting for the enhancement of photoelectrochemistry properties.

\section{Photoelectrochemical characterization measurements}

The linear sweep voltammetry (LSV) curves were obtained in three different experimental condition: in dark, under continuous light illumination (light-on) and under chopped light illumination (with $5 \mathrm{~s}$ light-on/light-off). The results of the electrode, using the $\mathrm{BiVO}_{4}$ (4) sample, are shown in Figures $3 \mathrm{a}$ and $3 \mathrm{~b}$, in $\mathrm{NaNO}_{3}$ and $\mathrm{Na}_{2} \mathrm{SO}_{4}$ electrolyte solution, respectively. Under continuous light illumination the photocurrent density increases with the anodic sweep potential (sweep to more positive potential, 0 to $+1.4 \mathrm{~V} v s . \mathrm{Ag} / \mathrm{AgCl}$ ) for both electrolytes solutions. Under chopped light illumination condition, it is possible to observe the reproducibility in the photocurrent density value. When the light is on, a jump of current is observed, and the reached current value is approximately the same obtained by continuous illumination. On the other hand, when the light is off, the current value is negligible, reached the same current value in dark condition (curve represented by dashed line). Then, this increases in the current density with the illumination of electrode shows the notable photoelectroactivity of this $\mathrm{BiVO}_{4}$ (4) sample. At $+1.2 \mathrm{~V}$ the photocurrent values are 0.06 and $0.182 \mathrm{~mA} \mathrm{~cm}^{-2}$ in $\mathrm{NaNO}_{3}$ and $\mathrm{Na}_{2} \mathrm{SO}_{4}$, respectively. This highest photocurrent density $\left(j_{\mathrm{s}}\right)$ value in $\mathrm{Na}_{2} \mathrm{SO}_{4}$, approximately three twice higher than $\mathrm{NaNO}_{3}$, must be associated with the fact of which this electrolyte solution favors the oxygen evaluation reaction at photoanode/electrolyte interface. ${ }^{23}$ Besides, the ionic strength may be a factor of contribution concerning
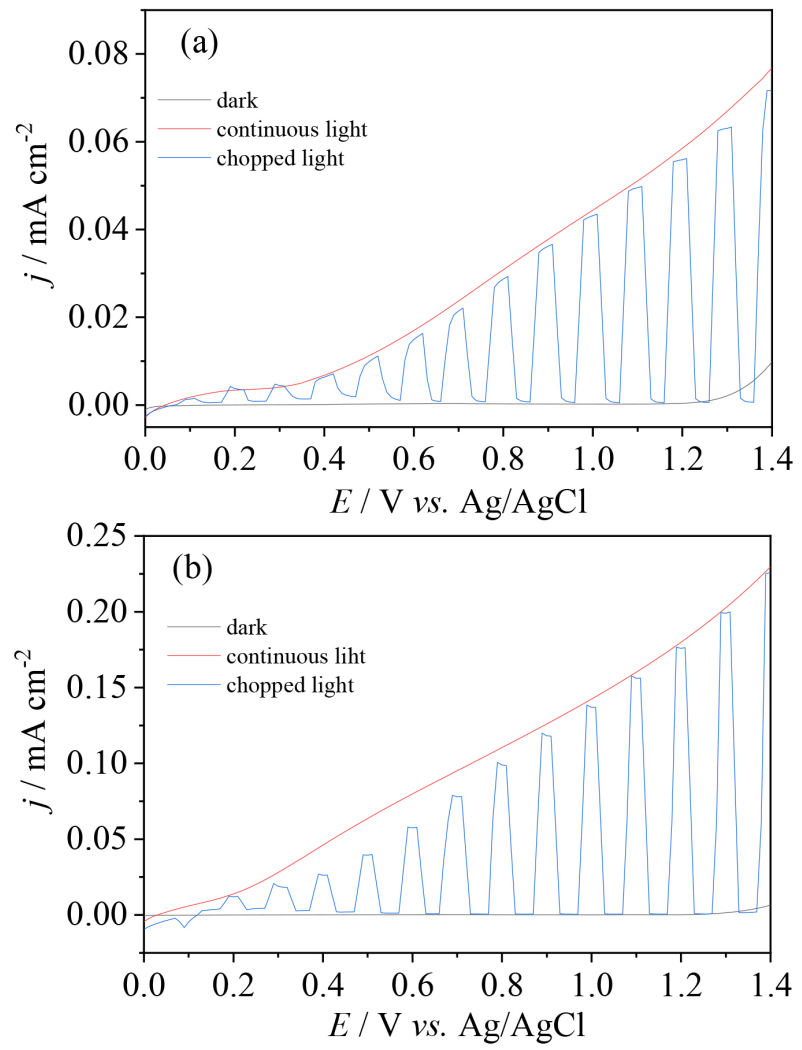

Figure 3. LSV curves at $10 \mathrm{mV} \mathrm{s}^{-1}$ scan rate, biased in the range 0 to $+1.4 \mathrm{~V}$ vs. $\mathrm{Ag} / \mathrm{AgCl}$ for $\mathrm{BiVO}_{4}$ (4) sample in the dark, continuous and chopped light illumination under (a) $\mathrm{NaNO}_{3}$ and (b) $\mathrm{Na}_{2} \mathrm{SO}_{4}$ solutions, both $0.1 \mathrm{~mol} \mathrm{~L}^{-1}$. 
more expressive photocurrent density values in $\mathrm{Na}_{2} \mathrm{SO}_{4}$ electrolyte solution. Others published works ${ }^{39-41}$ report the use of $\mathrm{Na}_{2} \mathrm{SO}_{4}$ solution as efficient electrolyte solution in $\mathrm{BiVO}_{4}$ photoanode in photoelectrochemical cells.

The sample $\mathrm{BiVO}_{4}(4)$ has presented the better photoelectrochemical performance when compared to the other samples $\mathrm{BiVO}_{4}(1), \mathrm{BiVO}_{4}(2)$ and $\mathrm{BiVO}_{4}$ (3), in both $\mathrm{NaNO}_{3}$ and $\mathrm{Na}_{2} \mathrm{SO}_{4}$ electrolyte solutions. The LSV curves of these other samples, in comparison with the LSV curve of $\mathrm{BiVO}_{4}$ (4), can be seen in SI section, Figure S3. This comparison shows that the photocurrent density obtained by $\mathrm{BiVO}_{4}$ (4) electrode is much higher than for the other samples. There is good indication that the better photoelectrochemical performance of $\mathrm{BiVO}_{4}$ (4) is due to morphological and microstructural properties. Among all samples, the $\mathrm{BiVO}_{4}$ (4) presents the narrowest band gap energy value, $2.27 \mathrm{eV}$ as viewed in Table 1 . Moreover, the Raman shift (Figure 1b), shows that the average $\mathrm{V}-\mathrm{O}$ bond length evaluated for this sample is $1.696 \AA$, which is little larger than for the other samples, and may cause a relaxed state in this $\mathrm{V}-\mathrm{O}$ bond, which favors the enhancement of the activity of oxygen evaluation reaction. ${ }^{39,41}$ In addition, and maybe the most important parameter due to its direct relation with the photoelectrochemical properties, is the homogeneity distribution, which in the case of sample $\mathrm{BiVO}_{4}$ (4) consists of particles with rods-shape format and nano-sized domain on the electrode surface, as can be seen in the SEM images in the Figure 2d. It is important to mention that the porosity and roughness levels on electrode surface are quite interesting for the enhancement of photoelectrochemistry properties.

The photochronoamperogram ( $\mathrm{j} v s . \mathrm{t}$ curves) of $\mathrm{BiVO}_{4}(4)$ sample obtained under chopped light illumination (with $10 \mathrm{~s}$ period of alternating light-off/light-on), can be seen in Figure $4 \mathrm{a}$ in $\mathrm{NaNO}_{3}$ and $\mathrm{Na}_{2} \mathrm{SO}_{4}$ solutions. The initial transient photocurrent decay (as observed from the $\mathrm{j} v s$. $\mathrm{t}$ curve) which takes place immediately after the current reaches its maximum value upon illumination, was evaluated in order to obtain an understanding of the charge recombination behavior in the prepared $\mathrm{FTO} / \mathrm{BiVO}_{4}$ electrode. When the light is on, the photocurrent density quickly reaches its maximum, however, this photocurrent density does not acquire stability, presenting a decay even before the light is turned off. This behavior in the shape of $\mathrm{j} v s$. $\mathrm{t}$ curve can be associated to the fast electron/ hole recombination process in the $\mathrm{BiVO}_{4}$ semiconductor material, as already discussed in a previous report. ${ }^{42}$ In the $\mathrm{NaNO}_{3}$ electrolyte solution, although the photocurrent density is lower than in $\mathrm{Na}_{2} \mathrm{SO}_{4}$, the photocurrent signal seems to be more stable. The photochronoamperograms of other samples $\left(\mathrm{BiVO}_{4}(1), \mathrm{BiVO}_{4}(2)\right.$ and $\left.\mathrm{BiVO}_{4}(3)\right)$ are shown in SI section, Figure S4. The decay profile of the j vs. $t$ curves (Figure S4) are very similar as well as the behavior of photocurrent stability, and the photocurrent values at $100 \mathrm{~s}$. The better photoelectrocatalytic performance of $\mathrm{BiVO}_{4}$ (4) sample becomes evident from these photochronoamperograms curves. The photocurrent value is higher than for the other samples, as already observed from the LSV measurements.
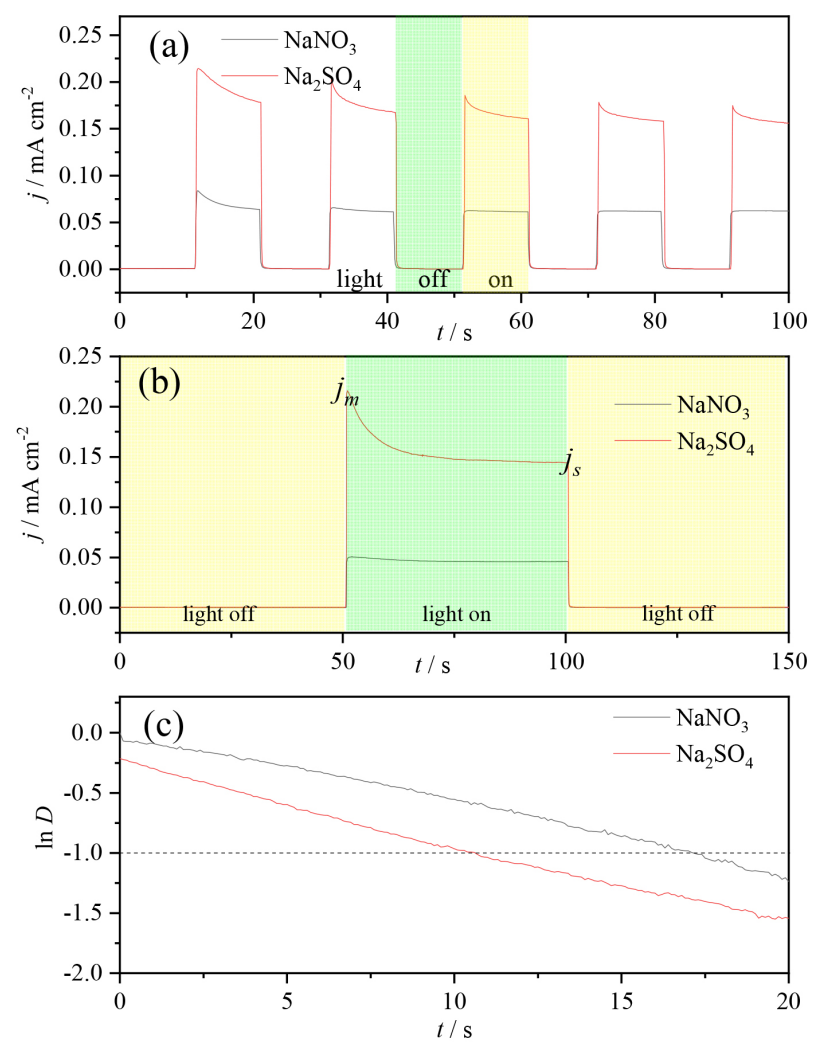

Figure 4. Photochronoamperogram of $\mathrm{BiVO}_{4}$ (4) sample with an applied potential of $+1.2 \mathrm{~V} v s$. $\mathrm{Ag} / \mathrm{AgCl}$ in $0.1 \mathrm{~mol} \mathrm{~L}^{-1}$ of different electrolyte solutions, $\mathrm{NaNO}_{3}$ and $\mathrm{Na}_{2} \mathrm{SO}_{4}$. (a) Chopped illumination condition with $10 \mathrm{~s}$ light-off/light-on until the time of $100 \mathrm{~s}$. (b) Chopped illumination condition with $50 \mathrm{~s}$ light-off/light-on/light-off until the time of $150 \mathrm{~s}$; (c) transient decay time $(\tau)$.

More photocronoamperometric measurements were carried out with a more prolonged time, aiming to obtain the estimated transient decay time $(\tau)$, which is a parameter associated with the lifetime of photogenerated electronhole pairs in $\mathrm{BiVO}_{4}$. The results from this experiment is shown in Figure 4b, where the alternating steps of light-off/ light-on/light-off were carried out with a period of $50 \mathrm{~s}$. The shape profile of obtained photochronoamperogram curve is similar to the results displayed in Figure 4a, where immediately after the light-on the current reaches its maximum value, evidencing the photoelectroactivity of this electrode. This maximum current, called spike current $\left(\mathrm{j}_{\mathrm{m}}\right)$, decreases as the chronoamperogram keeps running, until 
reaching a current value with stable behavior, called stable current $\left(\mathrm{j}_{\mathrm{s}}\right)$. Stable photocurrent $\left(\mathrm{j}_{\mathrm{s}}\right)$ values for $\mathrm{BiVO}_{4}(4)$ sample are 0.046 and $0.145 \mathrm{~mA} \mathrm{~cm}^{-2}$ in $\mathrm{NaNO}_{3}$ and $\mathrm{Na}_{2} \mathrm{SO}_{4}$, respectively. These values are summarized in Table 2, as well the $\mathrm{j}_{\mathrm{s}}$ values of other samples $\left(\mathrm{BiVO}_{4}(1), \mathrm{BiVO}_{4}(2)\right.$ and $\left.\mathrm{BiVO}_{4}(3)\right)$. The photochronoamperograms of these other samples are shown in SI section, Figure S5.

Table 2. Stable photocurrent density $\left(j_{\mathrm{s}}\right)$ values obtained from photochronoamperogram (50 s light on-off) curves for all electrodes samples

\begin{tabular}{lcc}
\hline \multirow{2}{*}{ Sample } & \multicolumn{2}{c}{$\left.\mathrm{j}_{\mathrm{s}} /(\mathrm{mA} \mathrm{cm})^{-2}\right)$} \\
\cline { 2 - 3 } & $\mathrm{NaNO}_{3}$ & $\mathrm{Na}_{2} \mathrm{SO}_{4}$ \\
\hline $\mathrm{BiVO}_{4}(1)$ & 0.0046 & 0.010 \\
$\mathrm{BiVO}_{4}(2)$ & 0.0064 & 0.020 \\
$\mathrm{BiVO}_{4}(3)$ & 0.0052 & 0.014 \\
$\mathrm{BiVO}_{4}(4)$ & 0.0460 & 0.145 \\
\hline
\end{tabular}

The photochronoamperogram of Figure $4 \mathrm{~b}$ can be further explored, by calculating the transient decay time $(\tau)$ of the electrode. As already mentioned, $\mathrm{j}_{\mathrm{m}}$ is the current spike, the current value when the light is switched on, and $\mathrm{j}_{\mathrm{s}}$ is the current density at the end of illumination time (the current density at the very moment where the recombination and charge generation reaches equilibrium). Figure $4 \mathrm{c}$, which analyze the transient decay time $(\tau)$ of electron-hole pairs in the $\mathrm{BiVO}_{4}$, gives more information on the charge carrier recombination process. This transient decay time was calculated from a logarithmic plot of parameter D, given by the equation $5 .^{43}$

$\ln \mathrm{D}=\frac{\left(\mathrm{j}_{\mathrm{t}}-\mathrm{j}_{\mathrm{s}}\right)}{\left(\mathrm{j}_{\mathrm{m}}-\mathrm{j}_{\mathrm{s}}\right)}$

where $\mathrm{j}_{\mathrm{t}}$ is the photocurrent at time $\mathrm{t}$, the transient decay time is defined as the time at which $\ln \mathrm{D}=-1.44-47$ The estimated values of decay time for the sample $\mathrm{BiVO}_{4}$ (4) are 10.70 and $17.22 \mathrm{~s}$ in $\mathrm{Na}_{2} \mathrm{SO}_{4}$ and $\mathrm{NaNO}_{3}$, respectively. These results show that in $\mathrm{NaNO}_{3}$ solution the transient decay time $(\tau)$ is longer than in $\mathrm{Na}_{2} \mathrm{SO}_{4}$ electrolyte solution, suggesting a slight decrease of the charge recombination rate at the interface electrode $/ \mathrm{NaNO}_{3}$ electrolyte solution. From the transient decay profile (curve $\ln \mathrm{D} v s$. $\mathrm{t}$ ), it is possible to observe a non-linear decay, indicating that the decay mechanism is rather complex, as mentioned in the paper of Bell et al. ${ }^{43}$

In order to analyze the behavior of the LSV curve profile in potential range of 0 to $+1.4 \mathrm{~V}$ in a condition which the photocurrent density seems to be stable, a steady-state experiment was performed. Steady-state data were obtained in the same experimental setup in a photochronoamperometric way by registering the stable current $\left(j_{\mathrm{s}}\right)$ in each applied potential. The applied potential starting at zero and, with a step of $0.2 \mathrm{~V}$ reaches $+1.4 \mathrm{~V}$. To each applied potential, a corresponding photocurrent density value is obtained. The plot of $\mathrm{j}_{\mathrm{p}} v s$. E steadystate curves can be seen in Figures $5 \mathrm{a}$ and $5 \mathrm{~b}$, where the electrode is in $\mathrm{NaNO}_{3}$ and $\mathrm{Na}_{2} \mathrm{SO}_{4}$ electrolyte solutions, respectively, along with the LSV curves (previously discussed in Figure 3). The profile of steady-state curves is similar to the LSV curves, in spite of the photocurrent density being a little lower. This lower photocurrent in steady-state condition was expected because the $\mathrm{j}_{\mathrm{s}}$ values are obtained in the instant that the recombination and charge generation reaches equilibrium. Besides, the onset potential (OP) parameter is also evaluated. The $\mathrm{OP}$ is estimated as the potential where the photocurrent density start to increase, and the shifting of OP to more cathodic potential is an important parameter, defined as the photocurrent density to achieve highly efficient photoelectrochemical systems. The OP is related to the thermodynamic and kinetics processes at electrode surface/ electrolyte solution. ${ }^{47} \mathrm{~A}$ shift of $100 \mathrm{mV}$ to more cathodic potential is observed in $\mathrm{Na}_{2} \mathrm{SO}_{4}$ solution compared to $\mathrm{NaNO}_{3}$ solution, showing a better photoelectrochemical
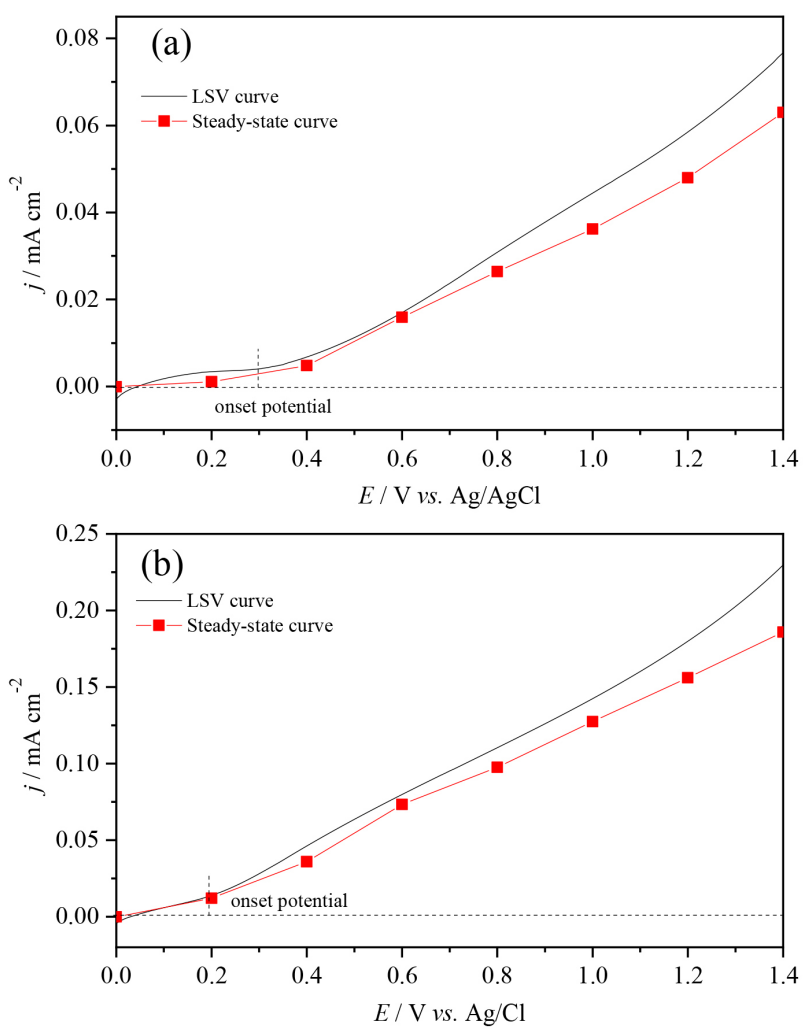

Figure 5. Steady-state polarization curves for $\mathrm{BiVO}_{4}$ (4) sample in (a) $\mathrm{NaNO}_{3}$ and (b) $\mathrm{Na}_{2} \mathrm{SO}_{4}$, both solutions $0.1 \mathrm{~mol} \mathrm{~L}^{-1}$. The LSV curves are also shown for comparison. 
performance in $\mathrm{Na}_{2} \mathrm{SO}_{4}$ solution, as already evidenced by the higher photocurrent density value.

Electrochemical impedance spectroscopy (EIS) measurements for the $\mathrm{BiVO}_{4}$ (4) electrode are shown in Figure 6, being used to analyze the kinetics of charge transfer at the interface electrode/electrolyte solution. The measurements were carried out in the dark and continuous light illumination condition, through a simpler equivalent Randles-Ershler (R-E) model circuit, ${ }^{48}$ modulated with three elements, $R_{S}, R_{c t}$ and $Q_{1}$. $R_{S}$ accounts for the resistances of the FTO conductor electrode, the external electrical contacts of the system and the electrolyte solution. ${ }^{49} \mathrm{R}_{\mathrm{ct}}$ is related to the direct charge-transfer resistance of $\mathrm{BiVO}_{4} /$ electrolyte solution interface, ${ }^{6}$ and can be estimated from the semicircular Nyquist plot. Due the porosity level of the $\mathrm{BiVO}_{4}$ film, as observed in the SEM image (Figure 2d), the $\mathrm{Q}_{1}$ was used instead of common capacitance to take into account the frequency dispersion, as reported by Hernández et al. ${ }^{49}$ and Dominguez-Benetton et al..$^{50}$
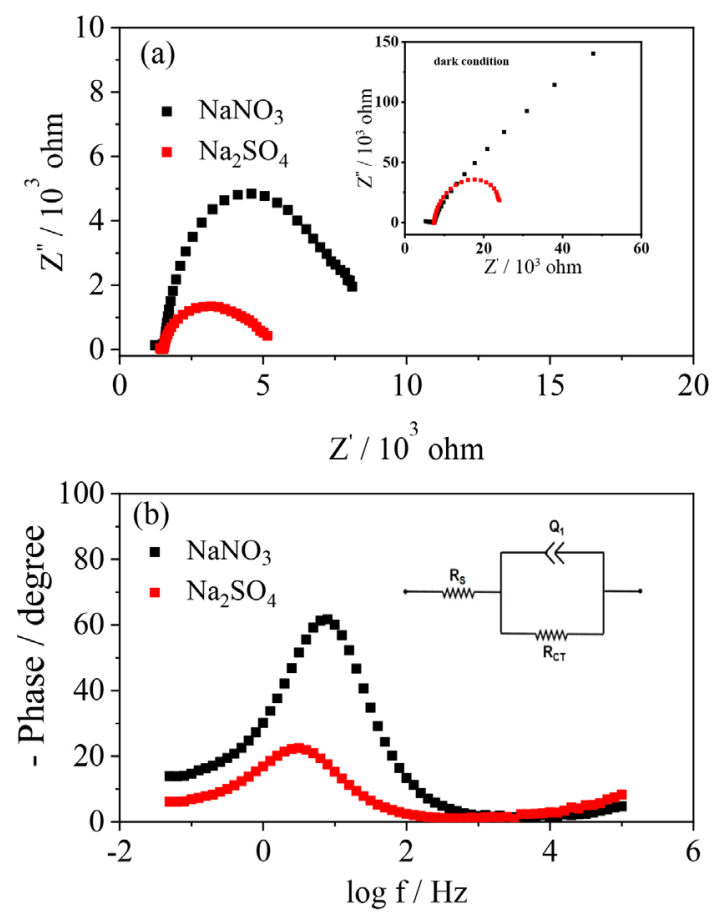

Figure 6. (a) Electrochemical impedance spectra of sample $\mathrm{BiVO}_{4}$ (4) electrode under continuous illumination in $\mathrm{NaNO}_{3}$ and $\mathrm{Na}_{2} \mathrm{SO}_{4}$ both $0.1 \mathrm{~mol} \mathrm{~L}^{-1}$. The measurements were carried out with an applied potential of $+1.2 \mathrm{~V} v s$. $\mathrm{Ag} / \mathrm{AgCl}, \mathrm{AC}$ amplitude of $20 \mathrm{mV}$ and frequency range of $0.05-100,000 \mathrm{~Hz}$. Inset: simple equivalent circuit used in these measurements and the impedance spectra in dark condition. (b) Bode plots of impedance spectra under light irradiation.

The effect of light incidence on charge-transfer resistance $\left(\mathrm{R}_{\mathrm{ct}}\right)$ in the $\mathrm{BiVO}_{4}$ semiconductor electrode is quite evident, when compared to the experiment in the dark condition. A smaller radius of the semicircle when the sample is placed under illumination leads to lower $R_{c t}$.
The $\mathrm{R}_{\mathrm{ct}}$ values obtained in dark condition are $150 \times 10^{3}$ and $27 \times 10^{3} \Omega$ in $\mathrm{NaNO}_{3}$ and $\mathrm{Na}_{2} \mathrm{SO}_{4}$, respectively. On the other hand, under illumination of the electrode, the $\mathrm{R}_{\mathrm{ct}}$ estimated values are $9.2 \times 10^{3}$ and $5.3 \times 10^{3} \Omega$ in $\mathrm{NaNO}_{3}$ and $\mathrm{Na}_{2} \mathrm{SO}_{4}$, respectively. These $\mathrm{R}_{\mathrm{ct}}$ values are in good agreement with the results obtained through the LSV curves and chronoamperometry that show the high efficiency of the InGaN LED light source used here for electron-hole pair generation in $\mathrm{BiVO}_{4}$ monoclinic structure.

Measurements leading to the Bode plots were also performed and are shown in Figure $6 \mathrm{~b}$ where the Bode plot was obtained when the sample is under light illumination, in $\mathrm{NaNO}_{3}$ and $\mathrm{Na}_{2} \mathrm{SO}_{4}$ solutions. From this diagram (phase angle $v s . \log$ frequency) one peak can be recognized, located at low frequency (below $1.5 \mathrm{~Hz}$ ), which is associated with the charge transfer at $\mathrm{BiVO}_{4}$ electrode/electrolyte solution interface ${ }^{51}$ In this case, the shifting to lower $\log f$ value in the $\mathrm{Na}_{2} \mathrm{SO}_{4}$ electrolyte solution shows that this solution favors the charge transfer process at electrode/electrolyte interface. These Bode plots are in good agreement with the estimated $R_{c t}$ value.

In addition, to contribute with a better understanding of the photoactivity performance enhancement of the $\mathrm{BiVO}_{4}$ electrode, the flat band potential $\left(\mathrm{E}_{\mathrm{fb}}\right)$ was estimated using Mott-Schottky (M-S) measurements. The $\mathrm{E}_{\mathrm{fb}}$ estimated values were obtained by M-S equation, ${ }^{52}$ (equation 6).

$\frac{1}{\mathrm{C}^{2}}=\frac{2}{\varepsilon q \varepsilon_{0} \mathrm{~N}_{\mathrm{D}} \mathrm{A}_{\mathrm{se}}^{2}}\left(\mathrm{E}-\mathrm{E}_{\mathrm{fb}}-\frac{\mathrm{k}_{\mathrm{b}} \mathrm{T}}{\mathrm{q}}\right)$

where $\mathrm{C}$ is the capacitance of space charge region, $\varepsilon$ is the relative permittivity of $\mathrm{BiVO}_{4}(86),{ }^{53} \varepsilon_{0}$ is the vacuum permittivity $\left(8.854 \times 10^{-12} \mathrm{~F} \mathrm{~m}^{-1}\right)$, q is the electron charge $\left(1.602 \times 10^{-19} \mathrm{C}\right), \mathrm{A}_{\mathrm{se}}$ is the surface area of the electrode $\left(\mathrm{cm}^{2}\right), \mathrm{N}_{\mathrm{D}}$ is the charge carrier concentration $\left(\mathrm{cm}^{-3}\right), \mathrm{E}$ is the applied potential $(\mathrm{V} v s . \mathrm{Ag} / \mathrm{AgCl}), \mathrm{E}_{\mathrm{fb}}$ is the flat band potential $(\mathrm{V} v s . \mathrm{Ag} / \mathrm{AgCl}), \mathrm{k}_{\mathrm{b}}$ is the Boltzmann's constant $\left(1.381 \times 10^{-23} \mathrm{~J} \mathrm{~K}^{-1}\right)$, and $\mathrm{T}$ is the temperature $(298 \mathrm{~K})$. Through the plot of $1 / \mathrm{C}^{2} v s$. E, the intercept of the straight tangent line with the $x$ axis in $1 / \mathrm{C}^{2}=0$ give us the estimated $\mathrm{E}_{\mathrm{fb}}$ values..$^{52}$

The M-S measurements were carried out under dark condition in both $0.1 \mathrm{~mol} \mathrm{~L}^{-1} \mathrm{NaNO}_{3}$ and $\mathrm{Na}_{2} \mathrm{SO}_{4}$ solutions with an applied frequency of $100 \mathrm{~Hz}$.

In the Figure 7 the M-S plot of $\mathrm{BiVO}_{4}$ samples is shown, where it is possible to observe the positive slope of plot $1 / \mathrm{C}^{2} v s$. E confirming the n-type conductivity of this material, meaning electrons are the majority charge carriers. The estimated $\mathrm{E}_{\mathrm{fb}}$ values for all $\mathrm{BiVO}_{4}$ samples can be seen in Table 3. In general, all of these $\mathrm{E}_{\mathrm{fb}}$ estimated values are in good agreement with published 
reports, ${ }^{54-59}$ using similar experimental conditions to these adopted in the present work, such as $\mathrm{Na}_{2} \mathrm{SO}_{4}$ electrolyte solution, $\mathrm{pH}$ condition in the range of 5-9, $\mathrm{Ag} / \mathrm{AgCl}\left(\mathrm{KCl} 3 \mathrm{~mol} \mathrm{~L}^{-1}\right)$ as reference electrode, $100-1000 \mathrm{~Hz}$ frequency applied range. For instance, some $\mathrm{E}_{\mathrm{fb}}$ reported values such as $-0.58 \mathrm{~V} v s$. $\mathrm{ag} / \mathrm{AgCl}$ in $0.1 \mathrm{~mol} \mathrm{~L}^{-1} \mathrm{Na}_{2} \mathrm{SO}_{4},{ }^{55}-0.46 \mathrm{~V} v \mathrm{~s}$. $\mathrm{Ag} / \mathrm{AgCl}$ in $0.5 \mathrm{~mol} \mathrm{~L}^{-1}$ $\mathrm{Na}_{2} \mathrm{SO}_{4},{ }^{56}-0.56 \mathrm{~V}$ vs. $\mathrm{Ag} / \mathrm{AgCl}$ in $0.2 \mathrm{~mol} \mathrm{~L}^{-1} \mathrm{Na}_{2} \mathrm{SO}_{4},{ }^{57}$ $-0.6 \mathrm{~V}$ vs. $\mathrm{Ag} / \mathrm{AgCl}$ in $0.5 \mathrm{~mol} \mathrm{~L}^{-1} \mathrm{Na}_{2} \mathrm{SO}_{4}{ }^{58}$ are quite similar values to the ones obtained here, and listed in Table 3, ranging from -0.49 to $-0.59 \mathrm{~V} v s$. $\mathrm{Ag} / \mathrm{AgCl}$.
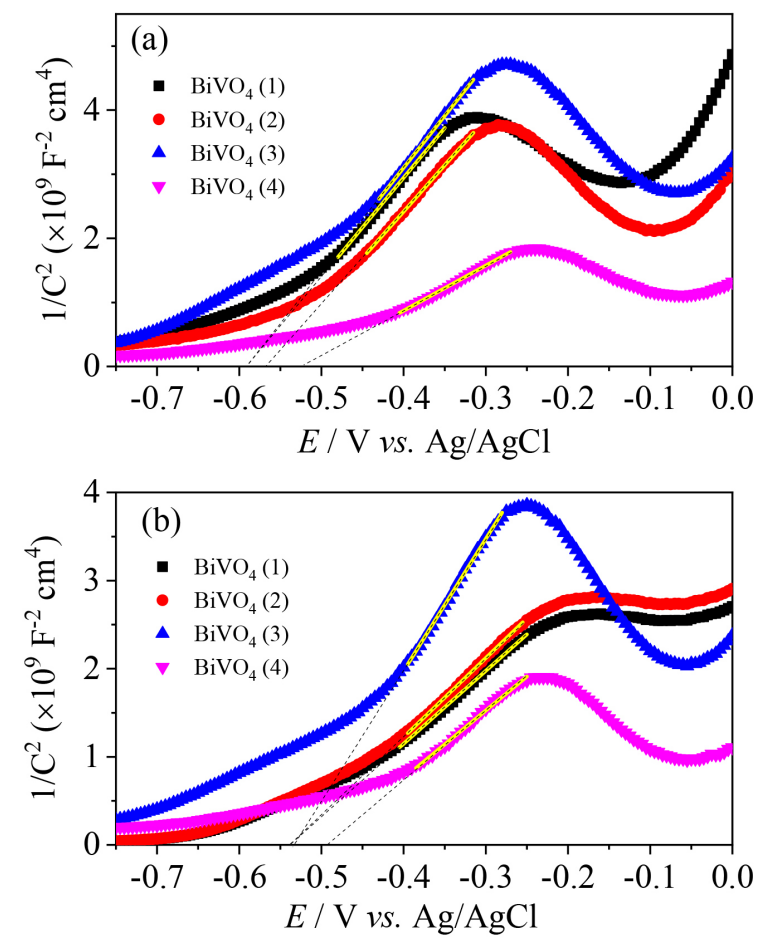

Figure 7. Mott-Schottky plots of $\mathrm{BiVO}_{4}$ samples in different $0.1 \mathrm{~mol} \mathrm{~L}^{-1}$ electrolyte solutions: (a) $\mathrm{NaNO}_{3}$ and (b) $\mathrm{Na}_{2} \mathrm{SO}_{4}$. Applied frequency of $100 \mathrm{~Hz}$.

Table 3. $\mathrm{E}_{\mathrm{fb}}$ and $\mathrm{N}_{\mathrm{D}}$ parameters obtained by M-S equation for $\mathrm{BiVO}_{4}$ electrodes

\begin{tabular}{lcclccc}
\hline \multirow{2}{*}{ Sample } & \multicolumn{2}{c}{$\mathrm{NaNO}_{3}$} & & \multicolumn{2}{c}{$\mathrm{Na}_{2} \mathrm{SO}_{4}$} \\
\cline { 2 - 3 } \cline { 5 - 6 } & $\mathrm{E}_{\mathrm{fb}} / \mathrm{V}$ & $\mathrm{N}_{\mathrm{D}} / \mathrm{cm}^{3}$ & & $\mathrm{E}_{\mathrm{fb}} / \mathrm{V}$ & $\mathrm{N}_{\mathrm{D}} / \mathrm{cm}^{3}$ \\
\hline $\mathrm{BiVO}_{4}(1)$ & -0.59 & $1.04 \times 10^{18}$ & & -0.54 & $1.84 \times 10^{18}$ \\
$\mathrm{BiVO}_{4}(2)$ & -0.56 & $1.11 \times 10^{18}$ & & -0.53 & $1.83 \times 10^{18}$ \\
$\mathrm{BiVO}_{4}(3)$ & -0.59 & $1.01 \times 10^{18}$ & & -0.53 & $1.19 \times 10^{18}$ \\
$\mathrm{BiVO}_{4}(4)$ & -0.51 & $2.25 \times 10^{18}$ & & -0.49 & $2.48 \times 10^{18}$ \\
\hline
\end{tabular}

$\mathrm{N}_{\mathrm{D}}$ : charge carrier concentration; $\mathrm{E}_{\mathrm{fb}}$ : flat band potential.

Based on these $\mathrm{E}_{\mathrm{fb}}$ values, it is possible to affirm that the $\mathrm{BiVO}_{4}$ (4) sample have presented a positive shift to more positive potential in both electrolyte solutions than the other samples, besides the lower slope in the linear region of M-S curves. It is reported in the literature ${ }^{55,56,60}$ that the lower slope of the linear region of M-S curves has some direct relationship with the carrier density $\left(\mathrm{N}_{\mathrm{D}}\right)$ in the bulk. In a way, this explanation is according with the estimated $\mathrm{N}_{\mathrm{D}}$ values obtained for $\mathrm{BiVO}_{4}(4)$, since this sample has presented higher $\mathrm{N}_{\mathrm{D}}$ value than other samples. These estimated $\mathrm{N}_{\mathrm{D}}$ values, which are also summarized in Table 3, were obtained by rearranging of M-S equation to equation $7,{ }^{52}$ and using the slope of the linear portion of the curve.

$\mathrm{N}_{\mathrm{D}}=\frac{2}{\varepsilon \mathrm{q} \varepsilon_{0} \mathrm{~A}_{\mathrm{se}}^{2}}\left(\frac{\mathrm{dE}}{\mathrm{d}\left(\frac{1}{\mathrm{C}^{2}}\right)}\right)$

where, $\left[\mathrm{dE} / \mathrm{d}\left(1 / \mathrm{C}^{2}\right)\right]$ is the slope of linear region of curve. These $\mathrm{N}_{\mathrm{D}}$ obtained values $\left(10^{18} \mathrm{~cm}^{-3}\right)$ are in good agreement with the others published papers using bare $\mathrm{BiVO}_{4} \cdot{ }^{61,62} \mathrm{In}$ addition, considering the $\mathrm{FTO} / \mathrm{BiVO}_{4}(4)$ electrode, results related to others $\mathrm{M}-\mathrm{S}$ measurements with different applied frequencies $(100,250$ and $500 \mathrm{~Hz})$ can be viewed in SI section, Figure S6. In general, a displacement in the $\mathrm{E}_{\mathrm{fb}}$ of $\mathrm{BiVO}_{4}$ towards more negative potential values is observed with the increase of applied frequency in both $\mathrm{Na}_{2} \mathrm{SO}_{4}$ and $\mathrm{NaNO}_{3}$ electrolyte solutions.

\section{Methyl orange photoelectrooxidation tests}

Due to the remarkable photoelectrochemical (PEC) performance of $\mathrm{BiVO}_{4}$ (4) electrode in both $\mathrm{NaNO}_{3}$ and $\mathrm{Na}_{2} \mathrm{SO}_{4}$ electrolyte solutions, which has been explained based on the physical and photoelectrochemical characterization results, the $\mathrm{BiVO}_{4}(4)$ sample was chosen to investigate the possible interaction of its surface face to the photoelectrochemical methyl orange (MO) degradation reaction. Some tests were carried out by cyclic voltammetry and chronoamperometry measurements using $5 \mathrm{~mL}$ of $\mathrm{MO} 0.1 \mathrm{mmol} \mathrm{L}^{-1}$ plus $0.1 \mathrm{~mol} \mathrm{~L}^{-1}$ of $\mathrm{NaNO}_{3}$ and $\mathrm{Na}_{2} \mathrm{SO}_{4}$ as support electrolytes. Figure 8 shows the cyclic voltammograms in dark condition and under continuous light illumination. In the dark, it is possible to observe the electroacticity of this electrode in the MO oxidation, by comparing the cyclic voltammograms in absence (black line) and in the presence of $\mathrm{MO}$ (red line). In the $\mathrm{NaNO}_{3}$ solution with the presence of $\mathrm{MO}$ two oxidation peaks are observed in the anodic scan, which are the peak $\mathrm{I}_{\mathrm{a}}$ at $0.42 \mathrm{~V}$ and $\mathrm{II}_{\mathrm{a}}$ at $0.8 \mathrm{~V}$, while in the cathodic scan one reduction peak is observed at $0.25 \mathrm{~V}$, named III $_{\mathrm{c}^{\prime}}$. The anodic $\mathrm{II}_{\mathrm{a}}$ peak is associated with irreversible redox reactions leading to cleavage of the azo bonds of MO. ${ }^{63}$ The cathodic peak associated with the $\mathrm{II}_{\mathrm{a}}$ anodic peak, forming the redox pair, does not appear in this voltammgram once this 
cathodic peak is located at $-0.3 \mathrm{~V}^{63}$ The peaks $\mathrm{I}_{\mathrm{a}}$ and $\mathrm{III}_{\mathrm{c}}$ correspond to the redox pair with semireversible behavior $\left(\mathrm{j}_{\mathrm{Ia}} / \mathrm{j}_{\mathrm{IIIC}} \neq 1\right)$. This semireversible redox pair is associated with the formation of unstable amine products, ${ }^{64,65}$ oxidized at $0.42 \mathrm{~V}$ and reduced at $0.25 \mathrm{~V}$. In the $\mathrm{Na}_{2} \mathrm{SO}_{4}$ solution with the presence of MO these same three peaks show up, however with a little shift in the $\mathrm{I}_{\mathrm{a}}$ and $\mathrm{III}_{\mathrm{c}}$ potential position. Under continuous light irradiation condition, these three peaks are also observed, which shows that the same electrochemical processes are taking place. Besides, under light illumination the faradaic current (anodic current), associated with the $\mathrm{II}_{\mathrm{a}}$ peak, is higher than in dark condition, showing the light effect on electrode surface, leading to an enhancement in the electroactivity. The obtained behavior of MO cyclic voltammogram is in good agreement with previous published papers. ${ }^{63-66}$
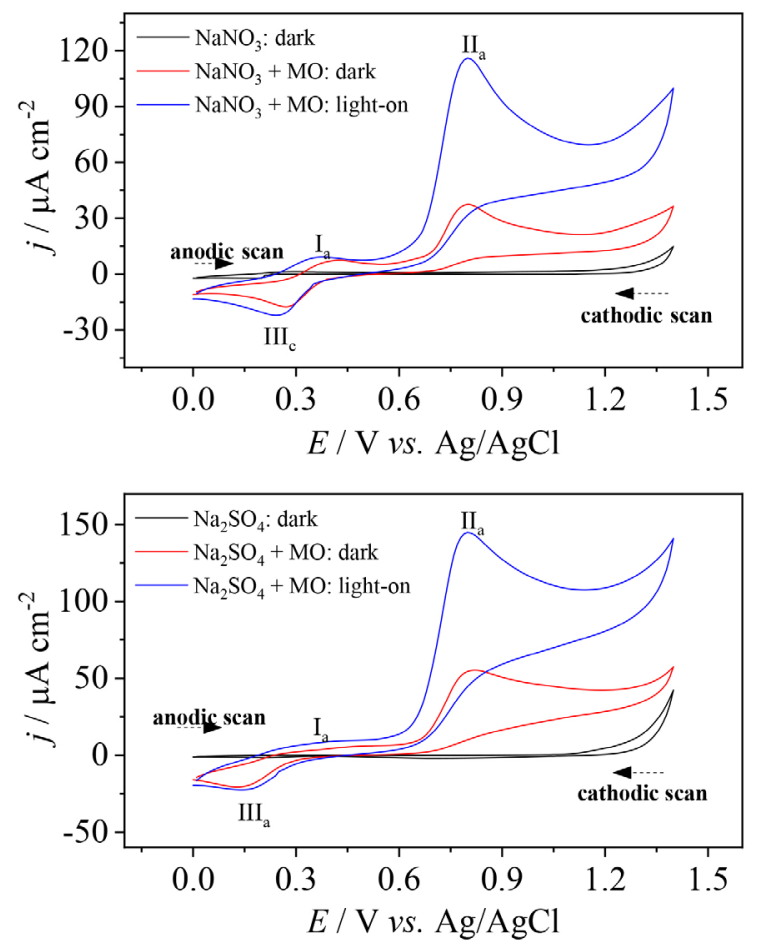

Figure 8. Cyclic voltammograms for $\mathrm{BiVO}_{4}$ (4) sample in both $0.1 \mathrm{~mol} \mathrm{~L}^{-1} \mathrm{NaNO}_{3}$ and $\mathrm{Na}_{2} \mathrm{SO}_{4}$ solutions in absence and presence of $\mathrm{MO}$ $0.1 \mathrm{mmol} \mathrm{L}^{-1}$. The experiment was carried out in the dark and under light illumination condition with sweep scan of $10 \mathrm{mV} \mathrm{s}^{-1}$.

The MO degradation reaction was observed by carrying out chronoamperometric measurements in $0.1 \mathrm{~mol} \mathrm{~L}^{-1}$ $\mathrm{NaNO}_{3}$ and $\mathrm{Na}_{2} \mathrm{SO}_{4}$ electrolyte solutions plus $0.1 \mathrm{mmol} \mathrm{L}^{-1}$ $\mathrm{MO}$ in different electrolysis time, under continuous light irradiation condition. Electrolysis experiments in the dark were also realized, aiming to verify the light effect in MO degradation. The applied potential chosen for electrolysis was $+0.8 \mathrm{~V}$ vs. $\mathrm{Ag} / \mathrm{AgCl}$, which is the potential where the MO electrooxidation occurs, as viewed in Figure 8 and discussed earlier. The UV-Vis absorbance spectra of degraded $\mathrm{MO}$ under continuous light illumination are shown in Figures $9 \mathrm{a}$ and $9 \mathrm{~b}$, in $\mathrm{NaNO}_{3}$ and $\mathrm{Na}_{2} \mathrm{SO}_{4}$ solutions, respectively, as well the dark condition experiment (inset). In spite of the short electrolysis time, $60 \mathrm{~min}$, the electrode was quite efficient in MO degradation reaction, as can be seen by the decrease in absorbance at about $453 \mathrm{~nm}$. The light effect in the MO degradation reaction using the FTO/ $\mathrm{BiVO}_{4}(4)$ electrode is quite evident when compared with the dark condition.

The degradation rate of $\mathrm{MO}$ is summarized in Figure $9 \mathrm{c}$, where the $C_{t} / C_{0}$ profile as function of time shows the decrease of the $453 \mathrm{~nm}$ absorption band of MO, as already mentioned. Through this $\mathrm{C}_{\mathrm{l}} / \mathrm{C}_{0}$ curve, applying the natural logarithm $\ln \left(C_{0} / C_{t}\right)$, Figure $9 d$, and make a plot of $\ln \left(C_{0} / C_{t}\right)$ $v s . t$, a linear behavior is observed, that suggest a pseudofirst-order kinetics model. Then, the pseudo-first-order rate constants $\left(\mathrm{k}_{\mathrm{obs}}\right)$ were calculated from the slopes of $\ln \left(\mathrm{C}_{0} / \mathrm{C}_{\mathrm{t}}\right) v s . \mathrm{t}$, according to equation 8 :

$\ln \left(\frac{\mathrm{C}_{0}}{\mathrm{C}_{\mathrm{t}}}\right)=\mathrm{k}_{\mathrm{obs}} \mathrm{t}$

where $\mathrm{C}_{0}$ and $\mathrm{C}_{\mathrm{t}}$ are initial concentration and the concentration in the time $\mathrm{t}$, respectively, $\mathrm{t}$ is the electrolysis time and $\mathrm{k}_{\mathrm{obs}}$ is the kinetic constant rate. The $\mathrm{k}_{\mathrm{obs}}$ obtained values under light condition are $4.74 \times 10^{-3}$ and $7.54 \times 10^{-3} \mathrm{~min}^{-1}$ in $\mathrm{NaNO}_{3}$ and $\mathrm{Na}_{2} \mathrm{SO}_{4}$ solutions, respectively, which are higher than dark condition $\left(1.43 \times 10^{-3}\right.$ and $1.14 \times 10^{-3} \mathrm{~min}^{-1}$ in $\mathrm{NaNO}_{3}$ and $\mathrm{Na}_{2} \mathrm{SO}_{4}$ solutions, respectively). These results using the $\mathrm{FTO} / \mathrm{BiVO}_{4}(4)$ sample electrode, are in good agreement with reported results ${ }^{67-72}$ and in comparison with some cases, ${ }^{67,69-72}$ the present results have presented better MO photoelectrodegradation efficiency.

For instance, the paper by Jiang et al. ${ }^{69}$ has evaluated the morphology-dependent photocatalytic performance of $\mathrm{BiVO}_{4}$ material for $\mathrm{MO}$ degradation under visible light illumination condition. Using the same monoclinic $\mathrm{BiVO}_{4}$ structure with porous spherical particle shape as surface morphology and surface area of $1.4 \mathrm{~m}^{2} \mathrm{~g}^{-1}$, their material reached a degradation percentage of $44 \%$ of MO solution in the prolonged time of $4 \mathrm{~h}$. In the present work, the $\mathrm{FTO} / \mathrm{BiVO}_{4}$ (4) electrode reached $42 \%$ of $\mathrm{MO}$ degradation in $\mathrm{Na}_{2} \mathrm{SO}_{4}$ electrolyte in a shorter time (only $60 \mathrm{~min}$ ). In another paper, Wang et al. ${ }^{71}$ have evaluated the MO degradation reaction using bare $\mathrm{BiVO}_{4}$ and with co-doping by boron and europium, synthesized by the sol-gel method. The authors have obtained the $\mathrm{k}_{\mathrm{obs}}$ values of $3.7 \times 10^{-3}, 7.1 \times 10^{-3}$ and $11.3 \times 10^{-3} \mathrm{~min}^{-1}$ for bare $\mathrm{BiVO}_{4}, \mathrm{~B}-\mathrm{BiVO}_{4}$ and $0.3 \mathrm{Eu}-\mathrm{B}-\mathrm{BiVO}_{4}$, respectively, in the degradation time of $60 \mathrm{~min}$. In the present paper, the $\mathrm{k}_{\mathrm{obs}}$ 

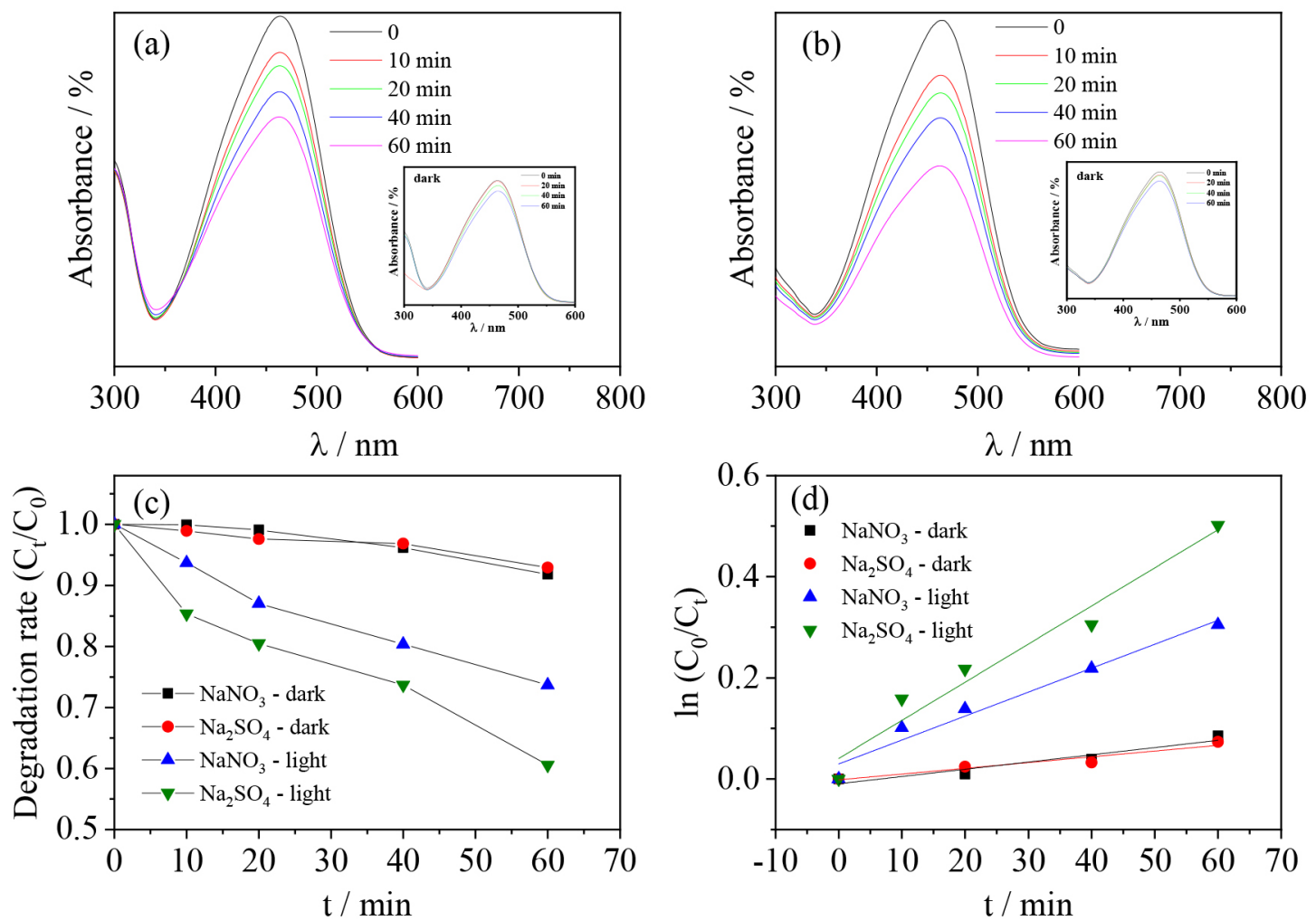

Figure 9. UV-Vis absorbance spectra of degraded $\mathrm{MO}$ in (a) $\mathrm{NaNO}_{3}$ and (b) $\mathrm{Na}_{2} \mathrm{SO}_{4}$ electrolyte solutions under continuous illumination condition. Inset: degradation in dark condition. (c) Change in the MO concentration under photoelectrolysis measurements. (d) Kinetic curves of the MO degradation reaction.

results obtained are $4.74 \times 10^{-3}$ and $7.54 \times 10^{-3} \mathrm{~min}^{-1}$, which are higher values than bare $\mathrm{BiVO}_{4}$ and $\mathrm{B}-\mathrm{BiVO}_{4}$ reported by Wang et al., ${ }^{71}$ and slightly lower than $0.3 \mathrm{Eu}-\mathrm{B}-\mathrm{BiVO}_{4}$. In another paper, Wang et al. ${ }^{72}$ have evaluated the MO degradation reaction using bare $\mathrm{BiVO}_{4}$ and with co-doping by boron and lanthanum, synthesized by sol-gel method. The authors have obtained the $\mathrm{k}_{\mathrm{obs}}$ values of $4.0 \times 10^{-3}$, $7.0 \times 10^{-3}$ and $8.0 \times 10^{-3} \mathrm{~min}^{-1}$ for bare $\mathrm{BiVO}_{4}, \mathrm{~B}_{-} \mathrm{BiVO}_{4}$ and $0.01 \mathrm{La}-\mathrm{B}-\mathrm{BiVO}_{4}$, respectively, in the degradation time of $60 \mathrm{~min}$. In comparison with the present paper, the $\mathrm{k}_{\mathrm{obs}}$ results obtained here are higher than bare $\mathrm{BiVO}_{4}$ and $\mathrm{B}-\mathrm{BiVO}_{4}$ $\mathrm{k}_{\mathrm{obs}}$ values and almost the same value of $0.01 \mathrm{La}-\mathrm{B}-\mathrm{BiVO}_{4}$.

This remarkable photoelectrochemical performance in the MO degradation reaction under visible light illumination by $\mathrm{FTO} / \mathrm{BiVO}_{4}$ (4) electrode is due to its morphological structure, with shape-elongated nano-size domain particles and considerable porosity and roughness levels on electrode surface, besides its narrow band gap energy $(2.5 \mathrm{eV})$. Then, taking into account these properties under visible light excitation, a high carrier density is generated on $\mathrm{BiVO}_{4}$ material. With the help of an applied external potential in the electrochemical system, the photogenerated electrons $\left(\mathrm{e}^{-}\right)$which are promoted to the conduction band of $\mathrm{BiVO}_{4}$ are immediately injected in the courter-electrode (platinum wire). On the other hand, the photogenerated holes $\left(\mathrm{h}^{+}\right)$in the valence band are free to react on electrode surface. These free holes density photogenerated on $\mathrm{BiVO}_{4}$ electrode surface are the key to an efficient $\mathrm{MO}$ demineralization reaction. A simplified MO photoelectrodegradation reaction mechanism on $\mathrm{BiVO}_{4}$ surface, based in paper of Garza-Galván et al. ${ }^{73}$ is proposed below, by two-pathway reaction sequence, the direct $\mathrm{MO}$ degradation (reaction 9 and 10) and MO degradation via 'OH-type radicals (reactions 9, 11-13) as follows:

$$
\begin{aligned}
& 2 \mathrm{BiVO}_{4}+\mathrm{h} v \rightarrow \mathrm{BiVO}_{4(\mathrm{~h}+)}+\mathrm{BiVO}_{4(\mathrm{e}-)} \\
& 2 \mathrm{BiVO}_{4(\mathrm{~h}+)}+\mathrm{MO} \rightarrow \text { intermediates } \rightarrow \\
& \text { degrated products }+\mathrm{BiVO}_{4} \\
& \mathrm{BiVO}_{4(\mathrm{~h}+)}+\mathrm{H}_{2} \mathrm{O} \rightarrow-\mathrm{OH}_{\text {ads }}+\mathrm{H}^{+}+\mathrm{BiVO}_{4} \\
& \mathrm{BiVO}_{4(\mathrm{~h}+)}+\mathrm{OH}_{\text {ads }} \rightarrow \cdot \mathrm{OH}_{\text {ads }}+\mathrm{BiVO}_{4} \\
& \mathrm{OH}_{\text {ads }}+\mathrm{MO} \rightarrow \text { intermediates } \rightarrow \\
& \text { degrated products }+\mathrm{BiVO}_{4}
\end{aligned}
$$

A more efficient pathway of MO demineralization reaction is obtained through the $\mathrm{OH}$-type radicals adsorbed on $\mathrm{BiVO}_{4}$ surface, attacking the aromatic rings of $\mathrm{MO}$ molecules and leading to the degradation.

\section{Conclusions}

In summary, the results have shown that the combination of PEG-600 and PVP in the SCS process, acting as 
stabilizing and surfactant agents, respectively, is quite efficient in obtaining monoclinic $\mathrm{BiVO}_{4}$ phase with high photoelectroactivity. No evidence of impurities or secondary crystalline phase in the $\mathrm{BiVO}_{4}$ samples was observed, from the characterization measurements carried out. The photoelectrochemical parameters, such as photocurrent density $\left(\mathrm{j}_{\mathrm{s}}\right)$, onset potential (OP), transient decay time $(\tau)$, charge-transfer resistence $\left(\mathrm{R}_{\mathrm{ct}}\right)$, flat band potential $\left(\mathrm{E}_{\mathrm{fb}}\right)$ and carrier density $\left(\mathrm{N}_{\mathrm{D}}\right)$ revealed the remarkable PEC performance of the as-prepared $\mathrm{BiVO}_{4}$ electrode (sample $\mathrm{BiVO}_{4}(4)$ ).

In addition, in the methyl orange (MO) degradation reaction the $\mathrm{FTO} / \mathrm{BiVO}_{4}$ (4) electrode have presented high photoelectroactivity, where the estimated kinetic constant rate $\left(\mathrm{k}_{\text {obs }}\right)$ is $4.74 \times 10^{-3}$ and $7.54 \times 10^{-3} \mathrm{~min}^{-1}$ in $\mathrm{NaNO}_{3}$ and $\mathrm{Na}_{2} \mathrm{SO}_{4}$ solutions, respectively.

These exciting results can be related to the morphological $\mathrm{BiVO}_{4}$ surface structure, consisting of elongated-shaped particles in the nano-sized domain, besides the considerable porosity and roughness levels on electrode surface. These results highlight the potential application of monoclinic $\mathrm{BiVO}_{4}$ obtained by the SCS/dip-coating process, as active electrode material for multifunctional photoelectrochemical system.

\section{Supplementary Information}

Supplementary information (Table S1 and Figures S1-S6) is available free of charge at http://jbcs.sbq.org.br as PDF file.

\section{Acknowledgments}

The authors wish to thank CNPq (process 406459/2016-9), Fundação Araucária (PROT. 38.647 SIT.22391), and INCT in Bioanalytics (FAPESP grant No. 2014/50867-3 and CNPq grant No. 465389/2014-7) for financial support, and LMEM-UEL for SEM analysis. They also acknowledge Dr Fenelon Martinho Lima Pontes for the help with XRD measurements and Dr Nilton Francelosi Azevedo Neto for the help with UV-Vis spectra of MO degraded solution. The two anonymous reviewers are also thanked for constructive criticism of an earlier manuscript version.

\section{References}

1. Yao, X.; Zhao, X.; Hu, J.; Xi, H.; Wang, D.; Cao, X.; Zhang, Z.; Huang, Y.; Chen, Z.; iScience 2019, 19, 976.

2. Venkatesan, R.; Velumani, S.; Ordon, K.; Makowska-Janusik, M.; Corbel, G.; Kassiba, A.; Mater. Chem. Phys. 2018, 205, 325.
3. Malathi, A.; Madhavan, J.; Ashokkumar, M.; Arunachalam, P.; Appl. Catal., A 2018, 555, 47.

4. Fujishima, A.; Honda, K.; Nature 1972, 238, 37.

5. Ager, J. W.; Shaner, M. R.; Walczak, K. A.; Sharp, I. D.; Ardo, S.; Energy Environ. Sci. 2015, 8, 2811.

6. Santos, W. S.; Almeida, L. D.; Afonso, A. S.; Rodriguez, M.; Mesquita, J. P.; Monteiro, D. S.; Oliveira, L. C. A.; Fabris, J. D.; Pereira, M. C.; Appl. Catal., B 2016, 182, 247.

7. Santos, W. S.; Rodriguez, M.; Afonso, A. S.; Mesquita, J. P.; Nascimento, L. L.; Patrocínio, A. O. T.; Silva, A. C.; Oliveira, L. C. A.; Fabris, J. D.; Pereira, N. C.; Sci. Rep. 2016, 6, 31406.

8. He, Y.; Zhang, C.; Hu, J.; Leung, M. K. H.; Energy Procedia 2019, 158, 2188

9. Silva, M. R.; Dall'Antonia, L. H.; Scalvi, L. V. A.; Santos, D. I.; Ruggiero, L. O.; Urbano, A.; J. Solid State Electrochem. 2012, $16,3267$.

10. Kumar, A.; Sharma, G.; Naushad, M.; Kumar, A.; Kalia, S.; Guo, C.; Mola, G. T.; J. Photochem. Photobiol., A 2017, 337, 118.

11. Hernández-Uresti, D. B.; Alanis-Moreno, C.; Sanchez-Martinez, D.; Mater. Sci. Semicond. Process. 2019, 102, 104585.

12. Cheng, L.; Jiang, T.; Yan, K.; Gong, J.; Zhang, J.; Electrochim. Acta 2019, 298, 561.

13. Tayebi, M.; Lee, B.-K.; Renewable Sustainable Energy Rev. 2019, 111, 332.

14. Park, Y.; McDonald, K. J.; Choi, K.-S.; Chem. Soc. Rev. 2013, 42, 2321.

15. Jia, Q.; Iwashina, K.; Kudo, A.; Proc. Natl. Acad. Sci. U. S. A. 2012, 109, 11564.

16. Silva, M. R.; Scalvi, L. V. A.; Neto, V. S. L.; Dall'Antonia, L. H.; J. Solid State Electrochem. 2016, 20, 1527.

17. Timmaji, H. K.; Chanmanee, W.; Tacconi, N. R.; Rajeshwar, K.; J. Adv. Oxid. Technol. 2011, 14, 95.

18. Rajeshwar, K.; Tacconi, N. R.; Chem. Soc. Rev. 2009, 38, 1984.

19. Chemseddine, A.; Ullrich, K.; Mete, T.; Abdi, F. F.; van de Krol, R.; J. Mater. Chem. A 2016, 4, 1723.

20. Serafim, J. A.; Afonso, R.; Lucilha, A. C.; Oliveira, L. A.; Silva, P. R. C.; Silva, M. R.; Sartori, E. R.; Dall'Antonia, L. H.; Quim Nova 2014, 37, 1158.

21. Kim, C. W.; Ji, S.; Kang, M. J.; Park, H.; Li, F.; Cheng, H.-M.; Kan, Y. S.; Mater. Today Energy 2019, 13, 205.

22. Tolod, K. R.; Hernández, S.; Russo, N.; Catalysts 2017, 7, 13.

23. Grigioni, I.; Corti, A.; Dozzi, M. V.; Selli, E.; J. Phys. Chem. C 2018, 122, 13969.

24. Ribeiro, F. W. P.; Gromboni, M. F.; Marken, F.; Mascaro, L. H.; Int. J. Hydrogen Energy 2016, 41, 17380.

25. Wang, M.; Xi, X.; Gong, C.; Zhang, X. L.; Fan, G.; Mater. Res. Bull. 2016, 74, 258.

26. Zhang, G.; Xu, Y.; Gao, D.; Sun, Y.; J. Alloys Compd. 2011, $509,885$.

27. Cui, Y.; Lai, X.; Li, L.; Hu, Z.; Wang, S.; Halpert, J. E.; Yu, R.; Wang, D.; ChemPhysChem 2012, 13, 2610. 
28. Song, Y.; You, H.; Huang, Y.; Yang, M.; Zheng, Y.; Zhang, L.; Guo, N.; Inorg. Chem. 2010, 49, 11499.

29. Li, X.-H.; Li, J.-X.; Li, G.-D.; Liu, D.-P.; Chen, J.-S.; Chem.Eur. J. 2007, 13, 8754.

30. Yin, W.; Zhou, L.; Gu, Z.; Tian, G.; Jin, S.; Yan, L.; Liu, X.; Xing, G.; Ren, W.; Liu, F.; Pan, Z.; Zhao, Y.; J. Mater. Chem. 2012, 22, 6974.

31. Wang, F.; Xue, X.; Liu, X.; Angew. Chem. 2008, 120, 920.

32. Cullity, B. D.; Stock, S. R.; Elements of X-ray Diffraction, $3^{\text {rd }}$ ed.; Prentice-Hall: New York, 2001.

33. Merupo, V.-I.; Velumani, S.; Ordon, K.; Errien, N.; Szaded, J.; Kassiba, A.-H.; CrystEngComm 2015, 17, 3366.

34. Xue, Y.; Wang, X.; Int. J. Hydrogen Energy 2015, 40, 5878.

35. Hardcastle, F. D.; Wachs, I. E.; J. Phys. Chem. 1991, 95, 5031.

36. Tokunaga, S.; Kato, H.; Kudo, A.; Chem. Mater. 2001, 13, 4624.

37. Nowak, M.; Kauch, B.; Szperlich, P.; Rev. Sci. Instrum. 2009, 80, 046107.

38. Mascaro, L. H.; Pockett, A.; Mitchels, J. M.; Peter, L. M.; Cameron, P. J.; Celorrio, V.; Fermin, D. J.; Sagu, J. S.; Wijayantha, K. G. U.; Kociok-Köhn, G.; Marken, F.; J. Solid State Electrochem. 2015, 19, 31.

39. Grigioni, I.; Stamplecoskie, K. G.; Jara, D. H.; Dozzi, M. V.; Oriana, A.; Cerullo, G.; Kamat, P. V.; Selli, E.; ACS Energy Lett. 2017, 2, 1362.

40. Su, J.; Guo, L.; Yoriya, S.; Grimes, C. A.; Cryst. Growth Des. 2010, 10, 856.

41. Berglund, S. P.; Flaherty, D. W.; Hahn, N. T.; Bard, A. J.; Mullins, C. B.; J. Phys. Chem. C 2011, 115, 3794.

42. Zhang, L.; Reisner, E.; Baumberg, J. J.; Energy Environ. Sci. 2014, 7, 1402.

43. Bell, N. J.; Ng, Y. H.; Du, A.; Coster, H.; Smith, S. C.; Amal, R.; J. Phys. Chem. C 2011, 115, 6004.

44. Zhang, H.; Cheng, C.; ACS Energy Lett. 2017, $2,813$.

45. Gao, L.; Li, F.; Hu, H.; Long, X.; Xu, N.; Hu, Y.; Wei, S.; Wang, C.; Ma, J.; Jin, J.; ChemSusChem 2018, 11, 2502.

46. Fang, W.; Tao, R.; Jin, Z.; Sun, Z.; Li, F.; Xu, L.; J. Alloys Compd. 2019, 797, 140.

47. Jung, H.; Chae, S. Y.; Shin, C.; Min, B. K.; Joo, O.-S.; Hwang, Y. J.; ACS Appl. Mater. Interfaces 2015, 7, 5788.

48. Kant, R.; Singh, M. B.; Electrochim. Acta 2015, 163, 310.

49. Hernández, S.; Thalluri, S. M.; Sacco, A.; Bensaid, S.; Saracco, G.; Russo, N.; Appl. Catal., A 2015, 504, 266.

50. Dominguez-Benetton, X.; Sevda, S.; Vanbroekhoven, K.; Pant, D.; Chem. Soc. Rev. 2012, 41, 7228.

51. Thalluri, S. M.; Rojas, R. M.; Rivera, O. D.; Hernández, S.; Russo, N.; Rodil, S. E.; Phys. Chem. Chem. Phys. 2015, 17, 17821.
52. Gelderman, K.; Lee, L.; Donne, S. W.; J. Chem. Educ. 2007, $84,685$.

53. Ye, K.-H.; Yu, X.; Qiu, Z.; Zhu, Y.; Luc, X.; Zhang, Y.; RSC Adv. 2015, 5, 34152.

54. Park, H. S.; Kweon, K. E.; Ye, H.; Paek, E.; Hwang, G. S.; Bard, A. J.; J. Phys. Chem. C 2011, 115, 17870.

55. Parmar, K. P. S.; Kang, H. J.; Bist, A.; Dua, P.; Jang, J. S.; Lee, J. S.; ChemSusChem 2012, 5, 1926.

56. Aguilera-Ruiz, E.; Garza-Galvan, M.; Zambrano-Robledo, P.; Ballesteros-Pacheco, J. C.; Vazquez-Arenas, J.; Peral, J.; García-Pérez, U. M.; RSC Adv. 2017, 7, 45885.

57. Moniz, S. J. A.; Zhu, J.; Tang, J.; Adv. Energy Mater. 2014, 4, 1301590

58. Sayama, K.; Nomura, A.; Arai, T.; Sugita, T.; Abe, R.; Yanagida, M.; Oi, T.; Iwasaki, Y.; Abe, Y.; Sugihara, H.; J. Phys. Chem. B 2006, 110, 11352.

59. Jia, A.; Kan, M.; Jia, J.; Zhao, Y.; J. Semicond. 2017, 38, 53004-1. 60. Berglund, S. P.; Rettie, A. J. E.; Hoang, S.; Mullins, C. B.; Phys. Chem. Chem. Phys. 2012, 14, 7065.

61. Ma, Y.; Pendlebury, S. R.; Reynal, A.; Formal, F. L.; Durrant, J. R.; Chem. Sci. 2014, 5, 2964.

62. Zhong, D. K.; Choi, S.; Gamelin, D. R.; J. Am. Chem. Soc. 2011, 133, 18370.

63. Zille, A.; Ramalho, P.; Tzanov, T.; Millward, R.; Aires, V.; Cardoso, M. H.; Ramalho, M. T.; Gubitz, G. M.; Cavaco-Paulo, A.; Biotechnol. Prog. 2004, 20, 1588.

64. Kalyuzhnyi, S.; Yemashova, N.; Fedorovich, V.; Water Sci. Technol. 2006, 54, 73.

65. Nie, C.; Sun, P.; Zhu, L.; Gao, S.; Wu, H.; Wang, B.; Environ. Chem. 2017, 14, 188.

66. Yusuf, H. A.; Redha, Z. M.; Baldock, S. J.; Fielden, P. R.; Goddard, N. J.; Microelectron. Eng. 2016, 149, 31.

67. Zhang, A.; Zhang, J.; Appl. Surf. Sci. 2010, 256, 3224.

68. Zhang, A.; Zhang, J.; J. Alloys Compd. 2010, 491, 631.

69. Jiang, H.; Dai, H.; Meng, X.; Zhang L.; Deng, J.; Ji, K.; Chinese J. Catal. 2011, 32, 939.

70. Ge, L.; Mater. Chem. Phys. 2008, 107, 465.

71. Wang, M.; Che, Y.; Niu, C.; Dang, M.; Dong, D.; J. Hazard. Mater. 2013, 262, 447.

72. Wang, M.; Che, Y.; Niu, C.; Dang, M.; Dong, D.; J. Rare Earth 2013, 31, 878.

73. Garza-Galván, M.; Zambrano-Robledo, P.; Vazquez-Arenas, J.; Romero-Ibarra, I.; Ostos, C.; Perale, J.; García-Pérez, U. M.; Appl. Surf. Sci. 2019, 487, 743.

Submitted: February 9, 2021 Published online: May 24, 2021 